Supporting Information

for

\title{
Revealing the Role of Polaron Distribution on the Performance of n- Type Organic Electrochemical Transistors
}

\author{
Junwei Shi, ${ }^{1,2 \dagger}$ Peiyun Li, ${ }^{1 \dagger}$ Xin-Yu Deng, ${ }^{1}$ Jingcao Xu, ${ }^{1}$ Zhen Huang, ${ }^{2}$ Yuqiu Lei,${ }^{3}$ \\ Yunfei Wang, ${ }^{4}$ Jie-Yu Wang, ${ }^{2}$ Xiaodan Gu, ${ }^{4}$ and Ting Lei ${ }^{1^{*}}$
}

${ }^{1}$ Key Laboratory of Polymer Chemistry and Physics of Ministry of Education, School of Materials Science and Engineering, Peking University, Beijing 100871, China

${ }^{2}$ Beijing National Laboratory for Molecular Science, College of Chemistry and

Molecular Engineering, Peking University, Beijing 100871, China

${ }^{3}$ College of Engineering, Peking University, Beijing 100871, China

${ }^{4}$ School of Polymer Science and Engineering, The University of Southern Mississippi, Hattiesburg, MS 39406, USA.

These authors contributed equally to this work.

*Corresponding authors: E-mail: tinglei@pku.edu.cn

Table of Contents

1. Experimental Details

2. Supplementary Tables and Figures

3. Polymer Synthesis

4. The Characterization Data of New Compounds

5. References 


\section{Experimental Details}

\section{Materials}

All the chemical reagents were purchased and used as received unless otherwise indicated. All air and water sensitive reactions were performed under a nitrogen atmosphere. Dichloromethane (DCM), Tetrahydrofuran (THF), Toluene, and $N, N$ Dimethylformamide (DMF) were dried by a JC Meyer solvent drying system before use. Ultradry solvents were obtained from J\&K reagent company.

\section{Chemical structure and optoelectronic property characterization}

${ }^{1} \mathrm{H}$ NMR and ${ }^{13} \mathrm{C}$ NMR spectra were recorded on Bruker ARX-400 (400 MHz). All chemical shifts were reported in parts per million (ppm). ${ }^{1} \mathrm{H}$ NMR chemical shifts were referenced to $\mathrm{CDCl}_{3}(7.26 \mathrm{ppm})$, and ${ }^{13} \mathrm{C}$ NMR chemical shifts were referenced to $\mathrm{CDCl}_{3}(77.16 \mathrm{ppm})$. Mass spectra were recorded on an FTMS Fourier transform highresolution mass spectrometer. Thermal gravity analyses (TGA) were carried out on a TA Instrument Q600 SDT analyzer, and differential scanning calorimetry (DSC) analyses were performed on a TA Instrument Q2000 analyzer. Absorption spectra were recorded on PerkinElmer Lambda 750 UV-vis spectrometer. Cyclic voltammograms (CV) were measured through an electrochemical workstation SP-300 (BioLogic Science Instruments). A standard three-electrode setup was established by employing polymer-coated ITO glass slides as the working electrode (WE), a block of platinum mesh as the counter electrode (CE), and an $\mathrm{AgCl} / \mathrm{Ag}$ pellet (Warner Instruments) as the reference electrode (RE), further calibrated against ferrocene $(\mathrm{Fc} / \mathrm{Fc}+)$. The measurements were carried out in an aqueous solution with $0.1 \mathrm{M} \mathrm{NaCl}$ or in acetonitrile with $0.1 \mathrm{M}$ tetrabutylammonium hexafluorophosphate as the supporting electrolyte with a scan rate of $50 \mathrm{mV} / \mathrm{s}$. Ionization potentials and electron affinity were obtained using the equation: $\mathrm{IP}=\left(E_{\mathrm{Ox}}-E_{\mathrm{Fc} / \mathrm{Fc}}{ }^{+}+4.8\right) \mathrm{eV}, \mathrm{EA}=\left(E_{\mathrm{Red}}-\underline{E}_{\mathrm{Fc} / \mathrm{Fc}}{ }^{+}+4.8\right)$ $\mathrm{eV}$. 


\section{Size exclusion chromatography measurement}

Polymer number-average molecular weight $\left(\mathrm{M}_{\mathrm{n}}\right)$ and molecular weight distributions $\left(\mathrm{PDI}=\mathrm{M}_{\mathrm{w}} / \mathrm{M}_{\mathrm{n}}\right)$ were measured by size exclusion chromatography (SEC). HFIP SEC analyses were performed on a Waters 1515 instrument equipped with a PLMIXED 7.5 $\times 50 \mathrm{~mm}$ guard column, two PLMIXED-C $7.5 \times 300$ columns, and a differential refractive index detector at $35{ }^{\circ} \mathrm{C}$ with a flow rate of $1 \mathrm{~mL} \mathrm{~min}{ }^{-1}$. The instrument was

calibrated with 10 PS standards, and chromatograms were processed with Waters Breeze software. 


\section{Supplementary Tables and Figures}

Table S1. Comparison of the OECT Performances for N-Type Polymers for OECTs.

\begin{tabular}{|c|c|c|c|c|c|c|c|c|c|}
\hline & $\begin{array}{c}\text { IP } \\
(\mathrm{eV})\end{array}$ & $\begin{array}{l}\mathbf{E A} \\
(\mathrm{eV})\end{array}$ & $\begin{array}{c}\mu C^{*} \\
(\mathrm{~F} / \mathrm{cm} \mathrm{V} \mathrm{s})\end{array}$ & $\begin{array}{c}\boldsymbol{\mu} \\
\left(\mathrm{cm}^{2} / \mathrm{V} \mathrm{s}\right)\end{array}$ & $\begin{array}{c}C^{*} \\
\left(\mathrm{~F} \mathrm{~cm}^{-3}\right)\end{array}$ & $\begin{array}{l}\boldsymbol{V}_{\text {th }} \\
(\mathrm{V})\end{array}$ & $\begin{array}{c}\boldsymbol{\tau}_{\text {on }} \\
(\mathrm{ms})\end{array}$ & $\begin{array}{c}\boldsymbol{\tau}_{\text {off }} \\
(\mathrm{ms})\end{array}$ & ref \\
\hline BBL & 5.9 & 4.1 & 0.65 & 0.0007 & 930 & 0.35 & 900 & 200 & {$[1,2]$} \\
\hline $\mathrm{P}(\mathrm{gNDI}-\mathrm{gT} 2)$ & 4.83 & 4.12 & 0.18 & 0.00045 & 397 & 0.35 & - & - & [3] \\
\hline $\mathrm{PgNaN}$ & 5.14 & 4.28 & 0.662 & 0.00662 & 100 & 0.37 & - & - & [4] \\
\hline f-BTI2TEG-T & 5.35 & 3.65 & 2.3 & 0.044 & 52 & 0.68 & 322 & 39 & {$[5]$} \\
\hline f-BTI2TEG-FT & 5.59 & 3.82 & 15.2 & 0.034 & 443 & 0.53 & 272 & 35 & {$[5]$} \\
\hline
\end{tabular}

Table S2. Summary of the Energy Levels and Molecular Weights of Polymers

\begin{tabular}{cccccccccc}
\hline & HOMO $^{\mathrm{a}}$ & $\mathbf{L U M O}^{\mathrm{a}}$ & $\mathbf{I P}^{\mathrm{b}}$ & $\mathbf{E A}^{\mathrm{b}}$ & $\mathbf{E}_{\mathbf{b}}{ }^{\mathrm{c}}$ & $\mathbf{E}_{\mathbf{g}}{ }^{\mathrm{c}}$ & $\mathbf{M}_{\mathbf{n}}{ }^{\mathrm{d}}$ & \\
& $(\mathrm{eV})$ & $(\mathrm{eV})$ & $(\mathrm{eV})$ & $(\mathrm{eV})$ & $(\mathrm{eV})$ & $(\mathrm{eV})$ & $(\mathrm{kDa})$ & $\mathbf{P D I}^{\mathrm{d}}$ \\
\hline $\mathrm{P}(\mathrm{gPzDPP}-2 \mathrm{C})$ & -5.40 & -3.54 & 5.38 & 3.90 & 1.48 & 1.60 & 90.89 & 3.47 \\
$\mathrm{P}(\mathrm{gPzDPP}-\mathrm{CT} 2)$ & -5.82 & -3.96 & 5.72 & 4.19 & 1.53 & 1.65 & 64.75 & 3.53 \\
\hline
\end{tabular}

${ }^{a}$ From DFT calculations. ${ }^{b}$ Estimated from the cyclic voltammetry (CV) measurement. ${ }^{c}$ Estimated from the UV-Vis-NIR spectra. ${ }^{\mathrm{d}}$ Using HFIP as the eluent.

Table S3. OECT Device Parameters of Two Polymers

\begin{tabular}{|c|c|c|c|c|c|c|c|c|}
\hline & $\begin{array}{c}L \\
(\mu \mathrm{m})\end{array}$ & $W / L$ & $\begin{array}{c}d \\
(\mathrm{~nm})\end{array}$ & $\begin{array}{c}g_{\mathrm{m}, \max } \\
(\mathrm{mS})\end{array}$ & $\begin{array}{c}W / L^{*} d \\
(\mathrm{~nm})\end{array}$ & $\begin{array}{l}V_{\text {th }} \\
\text { (V) }\end{array}$ & $\begin{array}{l}V_{\mathrm{GS}} \\
(\mathrm{V})\end{array}$ & $\begin{array}{c}\mu C^{*} \\
(\mathrm{~F} / \mathrm{cmVs})\end{array}$ \\
\hline \multirow{6}{*}{$\begin{array}{c}\text { P(gPzDPP- } \\
2 \mathrm{~T})\end{array}$} & 10.00 & 10.00 & 655.06 & 0.03 & 6550.60 & 0.56 & 0.78 & 0.22 \\
\hline & 10.00 & 10.00 & 475.79 & 0.02 & 4757.90 & 0.56 & 0.79 & 0.21 \\
\hline & 10.00 & 10.00 & 982.04 & 0.03 & 9820.40 & 0.57 & 0.79 & 0.15 \\
\hline & 10.00 & 10.00 & 942.33 & 0.04 & 9423.30 & 0.57 & 0.79 & 0.18 \\
\hline & 10.00 & 10.00 & 403.37 & 0.01 & 4033.70 & 0.57 & 0.78 & 0.14 \\
\hline & 10.00 & 10.00 & 795.20 & 0.03 & 7952.00 & 0.57 & 0.79 & 0.17 \\
\hline Average & & & & & & 0.57 & & 0.18 \\
\hline
\end{tabular}




\begin{tabular}{|c|c|c|c|c|c|c|c|c|}
\hline \multirow{3}{*}{$\begin{array}{c}\text { P(gPzDPP } \\
\text { CT2) }\end{array}$} & 10.00 & 10.00 & 55.02 & 0.02 & 550.17 & 0.32 & 0.59 & 1.20 \\
\cline { 2 - 9 } & 10.00 & 10.00 & 55.02 & 0.02 & 550.17 & 0.32 & 0.59 & 1.39 \\
\cline { 2 - 9 } & 10.00 & 10.00 & 55.02 & 0.02 & 550.17 & 0.32 & 0.60 & 1.36 \\
\cline { 2 - 9 } & 10.00 & 10.00 & 55.02 & 0.02 & 550.17 & 0.32 & 0.59 & 1.34 \\
\cline { 2 - 9 } & 10.00 & 10.00 & 68.22 & 0.03 & 682.20 & 0.31 & 0.56 & 1.72 \\
\cline { 2 - 9 } & 10.00 & 10.00 & 59.69 & 0.02 & 596.90 & 0.31 & 0.59 & 1.15 \\
\hline \multirow{2}{*}{ Average } & & & & & & 0.32 & & 1.36 \\
\hline
\end{tabular}
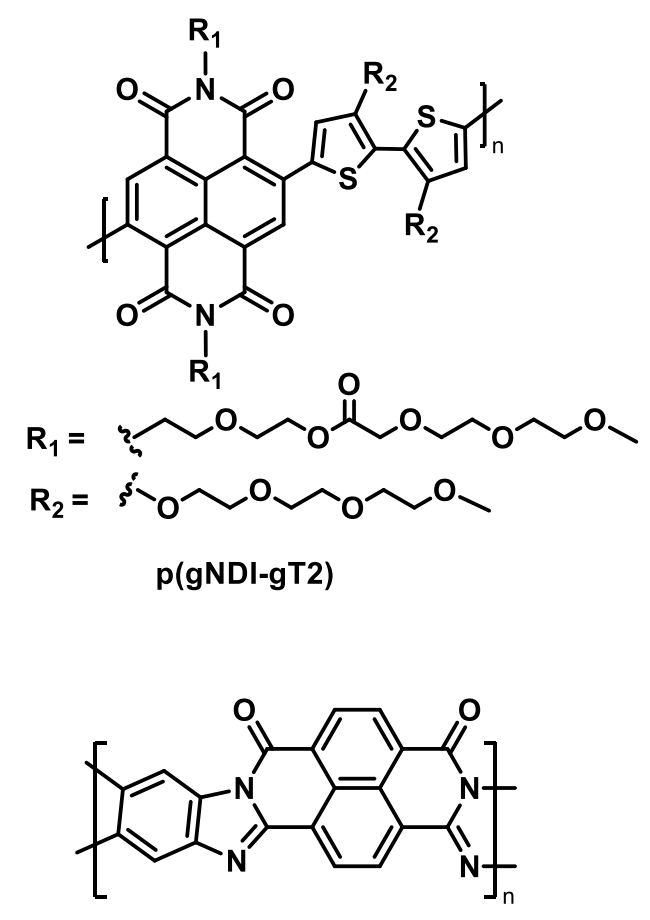

BBL
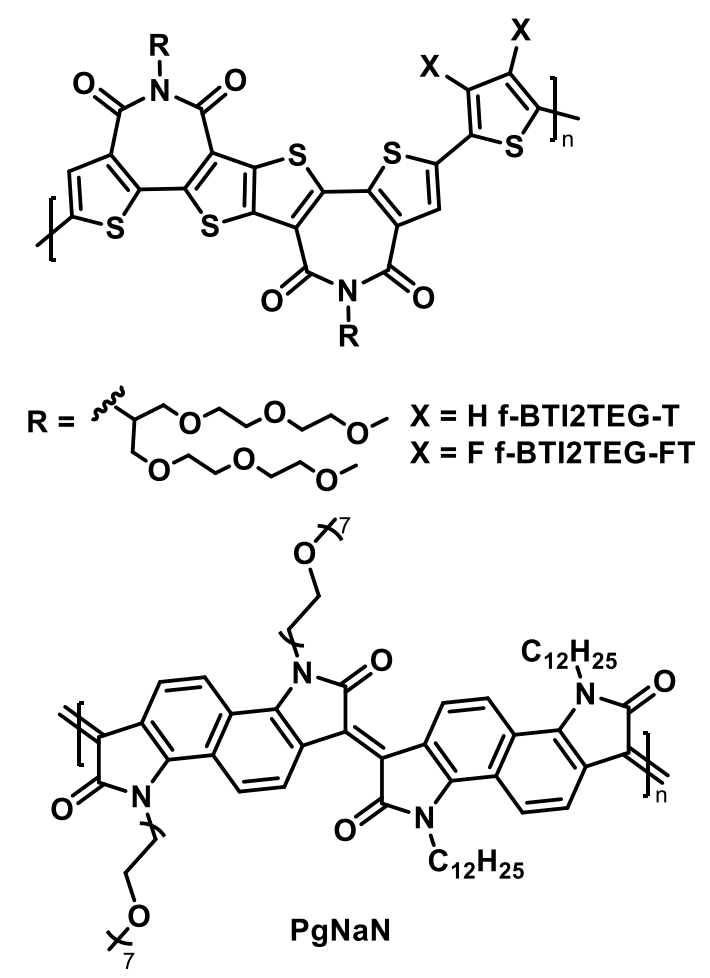

Figure S1 Molecular structures of several n-type OECT polymers in Table S1.
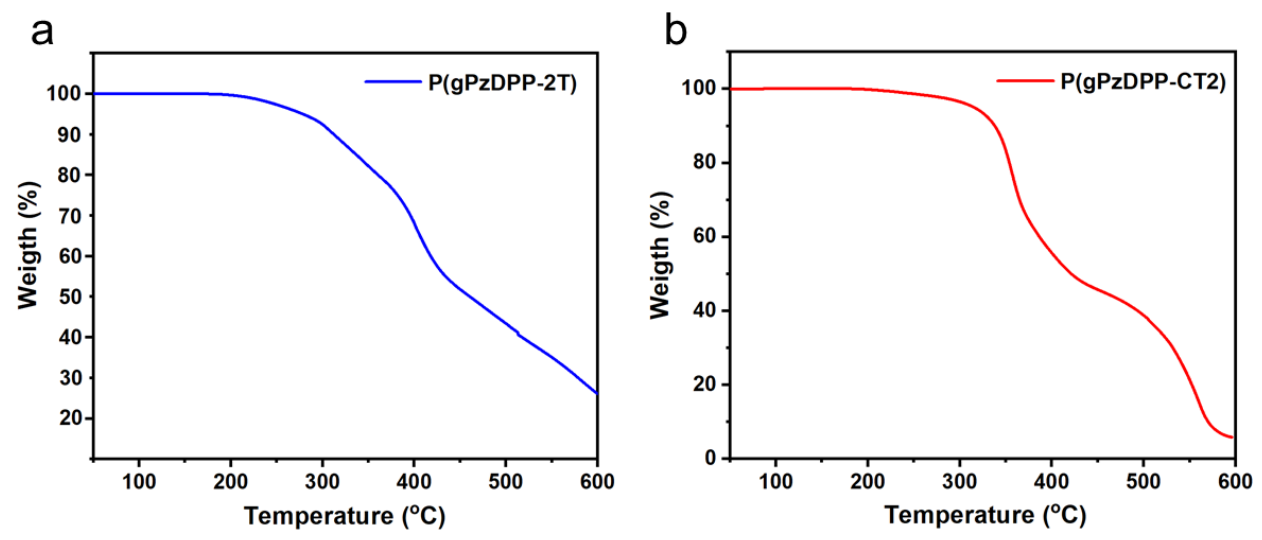
Figure S2 Thermal gravity analysis (TGA) of (a) P(gPzDPP-2T) and (b) P(gPzDPP-CT2).

a

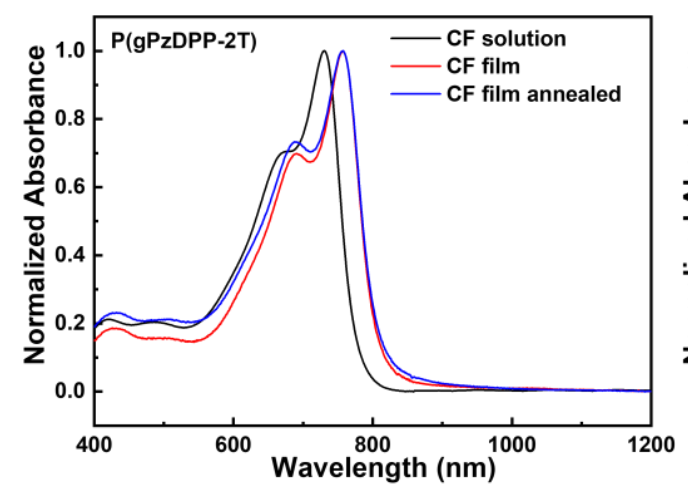

b

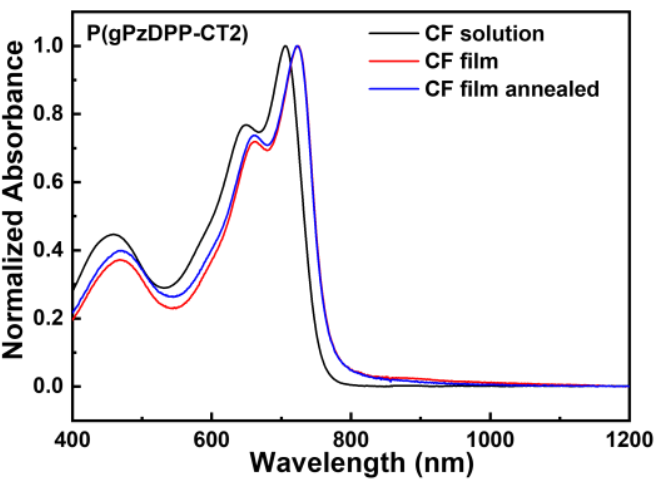

Figure S3 Normalized UV-vis-NIR absorption spectra of (a) P(gPzDPP-2T) and (b) P(gPzDPP-

CT2) in solution, in thin film, and in annealed thin film $\left(80^{\circ} \mathrm{C}, 10 \mathrm{~min}\right)$.

$$
\text { a }
$$

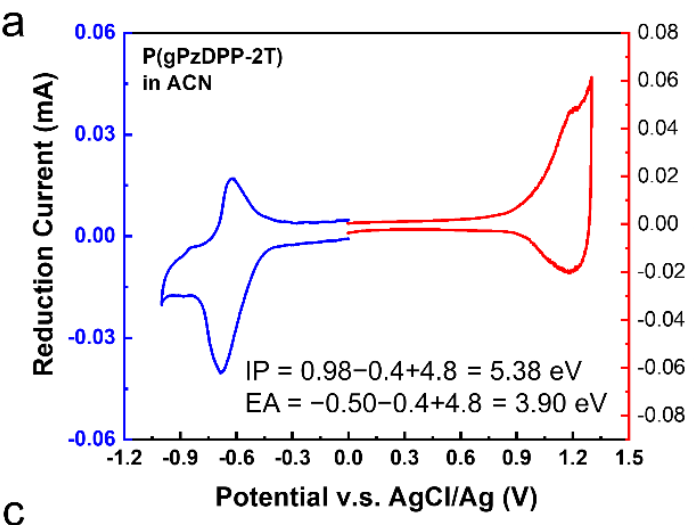

C

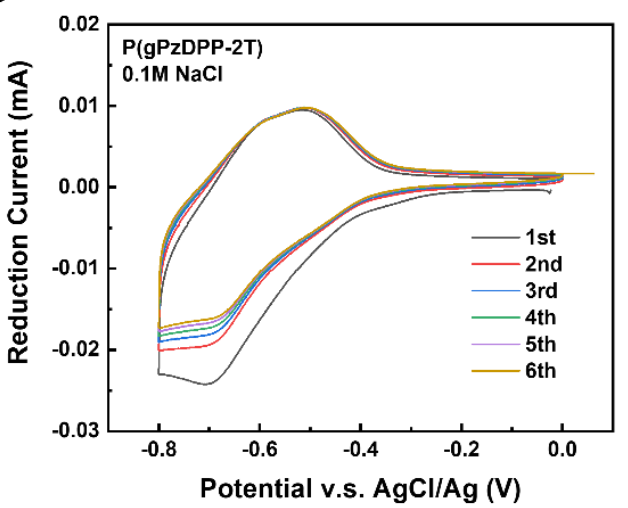

$\mathrm{b}$

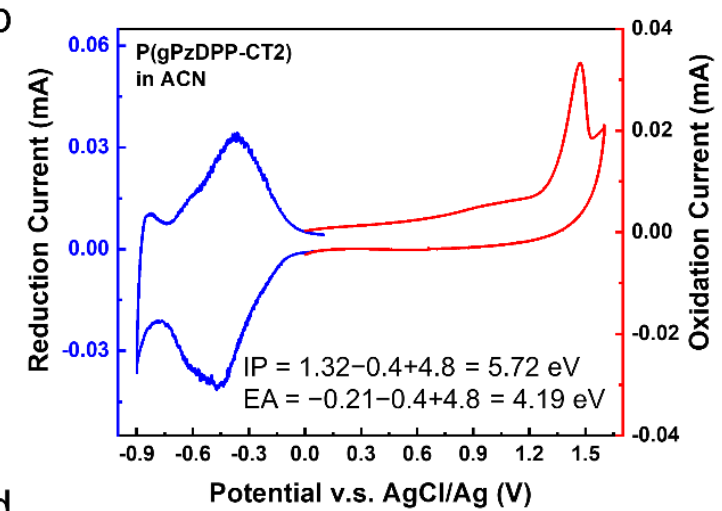

d

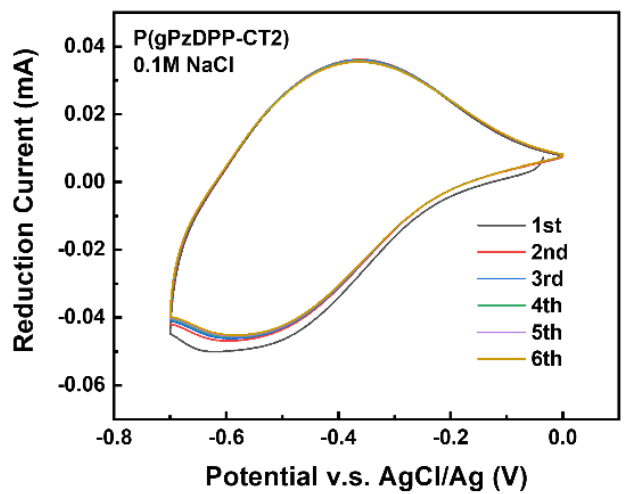

Figure S4 Cyclic voltammograms of (a, c) P(gPzDPP-2T) and (b, d) P(gPzDPP-CT2), in acetonitrile solution with $0.1 \mathrm{M}$ tetrabutylammonium hexafluorophosphate or $0.1 \mathrm{M} \mathrm{NaCl}$ as the electrolyte. 
a
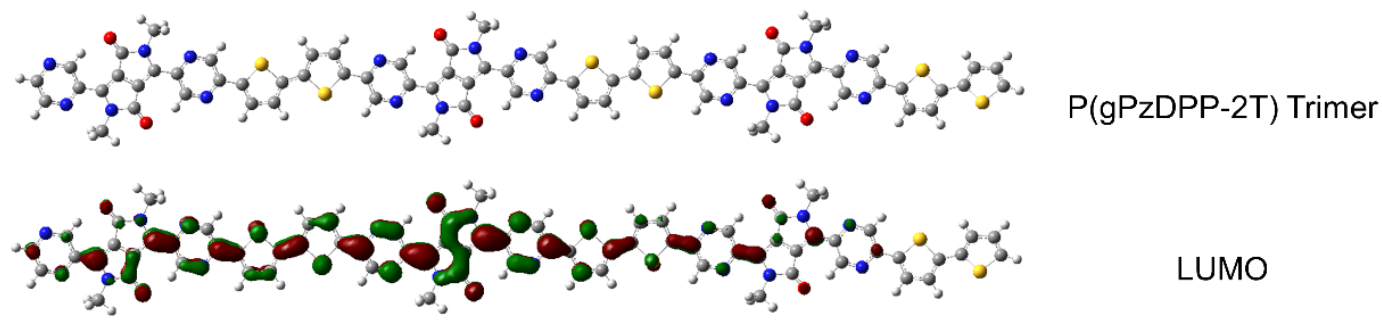

LUMO

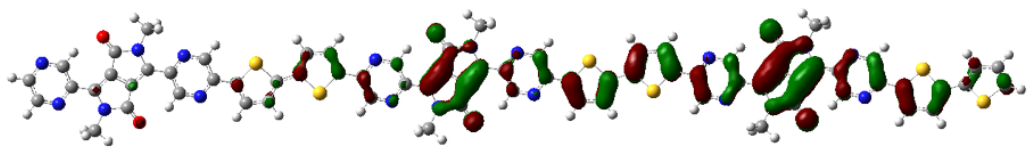

HOMO

b
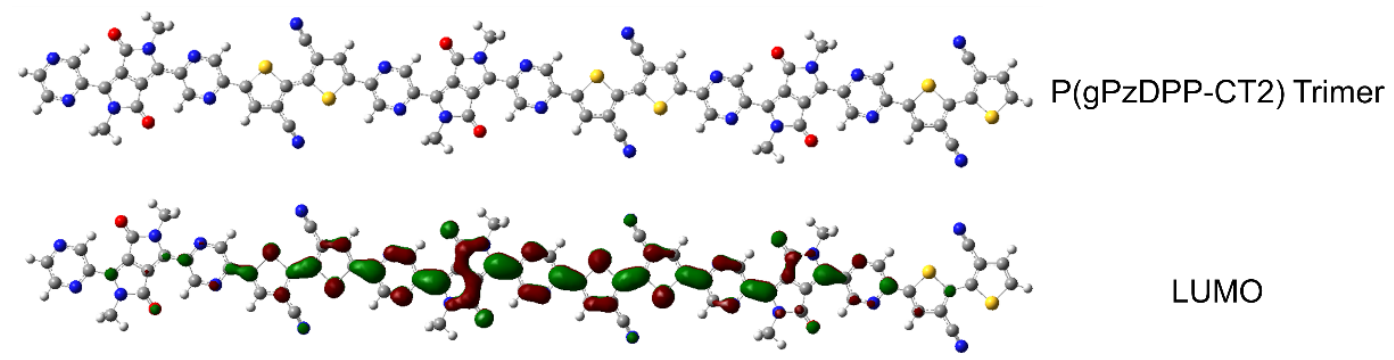

LUMO

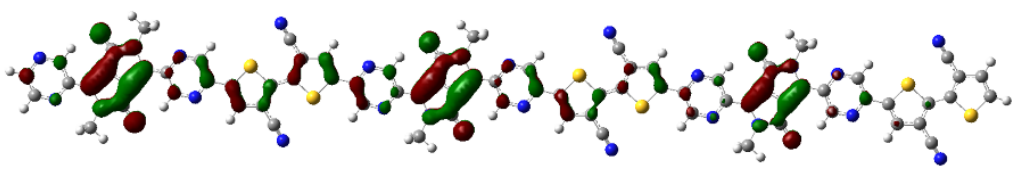

HOMO

Figure S5 DFT-optimized geometries and molecular frontier orbitals of the trimer of (a) P(gPzDPP2T) and (b) P(gPzDPP-CT2). Calculations were performed at B3LYP/6-311G(d,p) level. Branched glycol side chains were replaced with methyl groups to simplify the calculation.

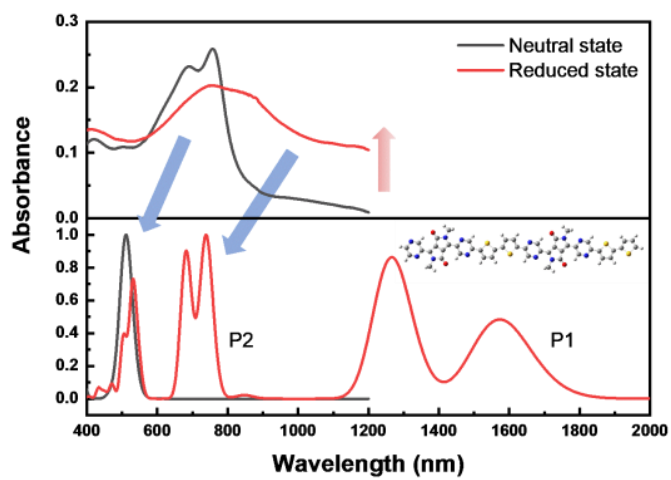

b

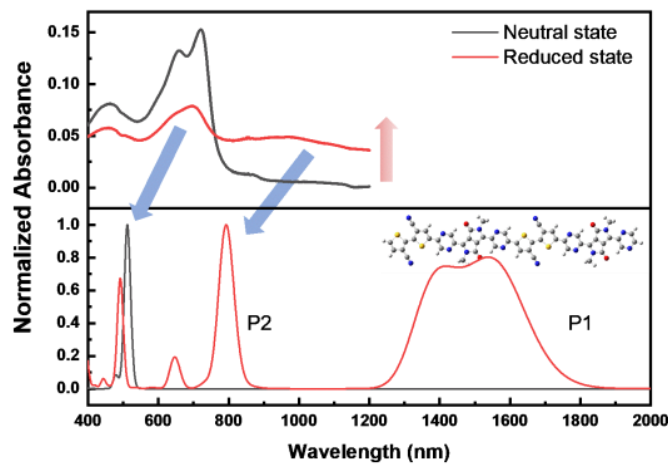

Figure S6 Experimental and calculated UV-vis-NIR absorption spectra for the neutral and reduced states of (a) P(gPzDPP-2T) and (b) P(gPzDPP-CT2). The top is the experimental spectrum and the bottom is the calculated spectrum. Oligomers $(n=2)$ were used for time-dependent densityfunctional theory (TDDFT) calculation. 
a

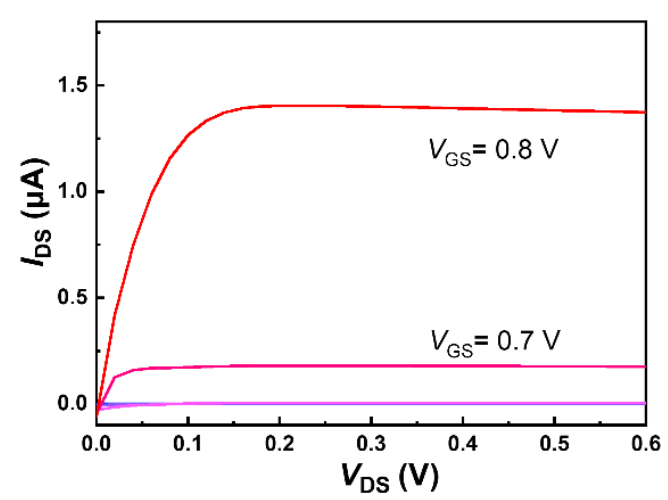

b

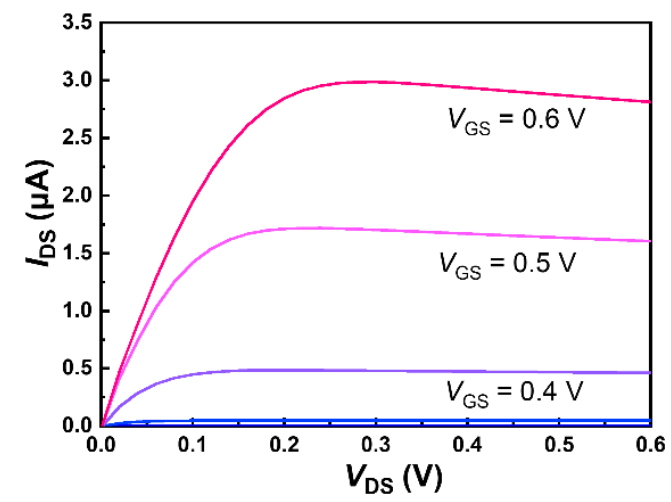

Figure S7 Output characteristics of (a) P(gPzDPP-2T) and (b) P(gPzDPP-CT2) based OECT devices.

a

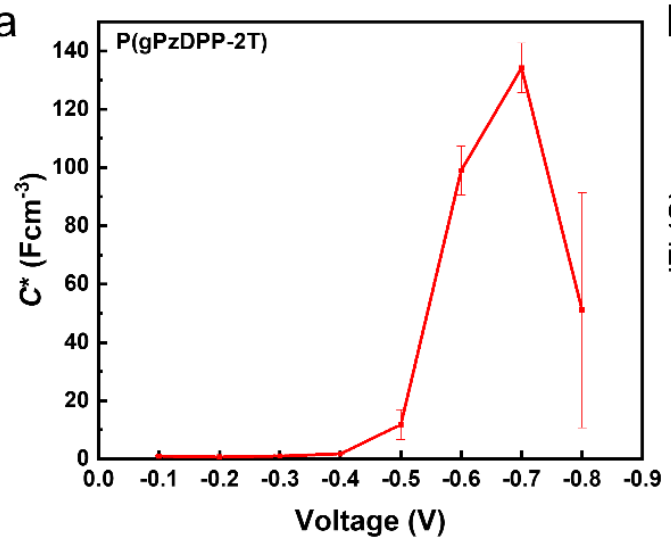

C

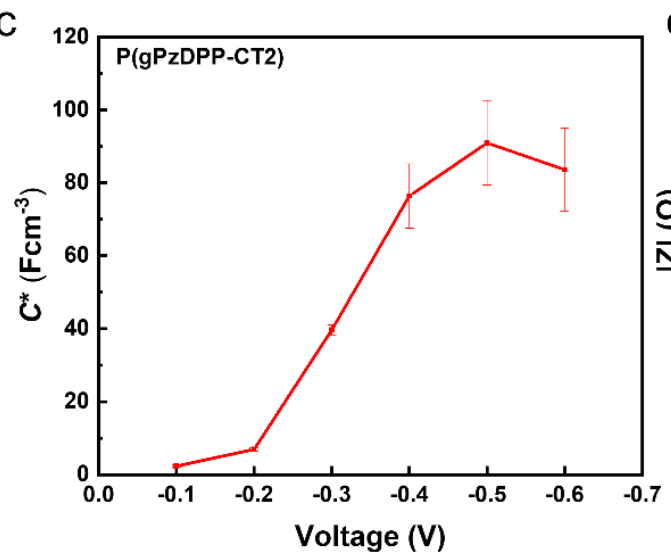

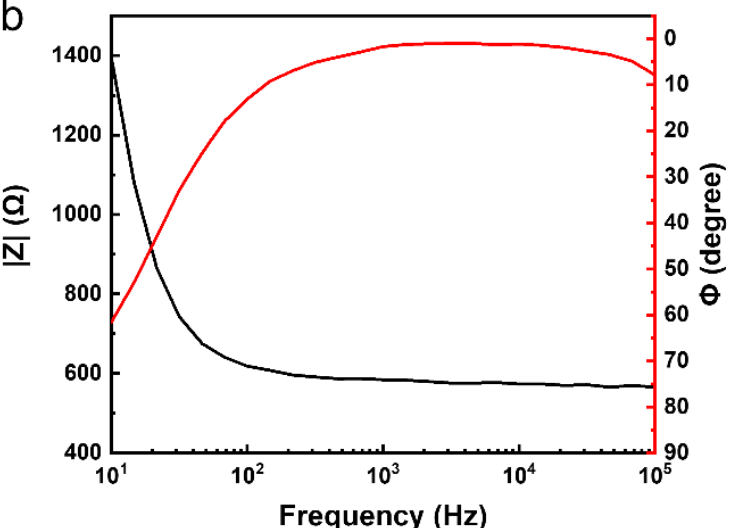

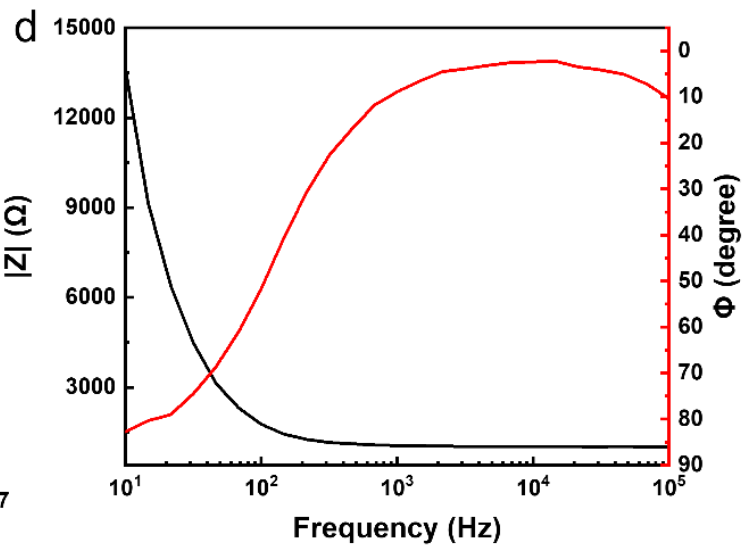

Figure S8 Capacitive behaviors of both polymers. (a, c) Voltage-capacitance relationship of P(gPzDPP-2T) and P(gPzDPP-CT2) measured through the electrochemical impedance spectrum. (b, d) The corresponding Bode and phase plot of P(gPzDPP-2T) and P(gPzDPP-CT2) with a bias of $-0.7 \mathrm{~V}$ and $-0.5 \mathrm{~V}$, respectively. 


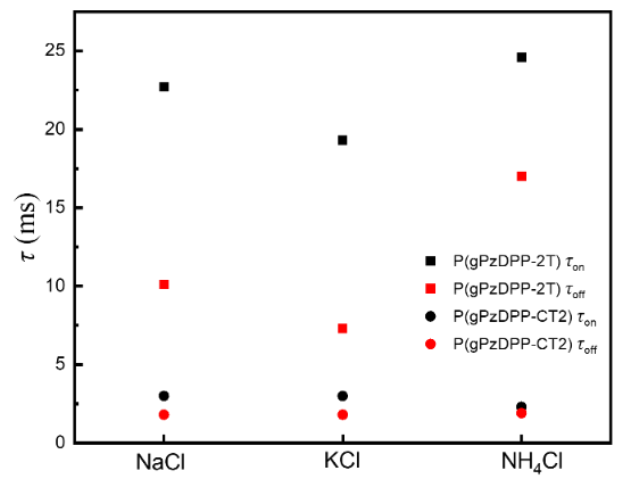

Figure S9 Summary of the response time of OECTs based on P(gPzDPP-2T) and P(gPzDPP-CT2) with different electrolytes. One device for each polymer was tested with three kinds of electrolyte, aqueous solutions of $\mathrm{NaCl}, \mathrm{KCl}$, and $\mathrm{NH}_{4} \mathrm{Cl}$. The electrolytes are chosen because of their potential application in bioelectronics. The ion mobility is around $7.6 \times 10^{-4} \mathrm{~cm}^{2} / \mathrm{Vs}$ for $\mathrm{NH}_{4}{ }^{+}$and $\mathrm{K}^{+}, 5.0 \times$ $10^{-4} \mathrm{~cm}^{2} / \mathrm{Vs}$ for $\mathrm{Na}^{+[6]}$. The OECTs of $\mathrm{P}(\mathrm{gPzDPP}-2 \mathrm{~T})$ and $\mathrm{P}(\mathrm{gPzDPP}-\mathrm{CT} 2)$ show almost the same response time in the three kinds of electrolytes, which is not proportional to the ion mobility reported in literature. Therefore, we believe that ionic mobility has little effect on the response speed of the devices in our work.
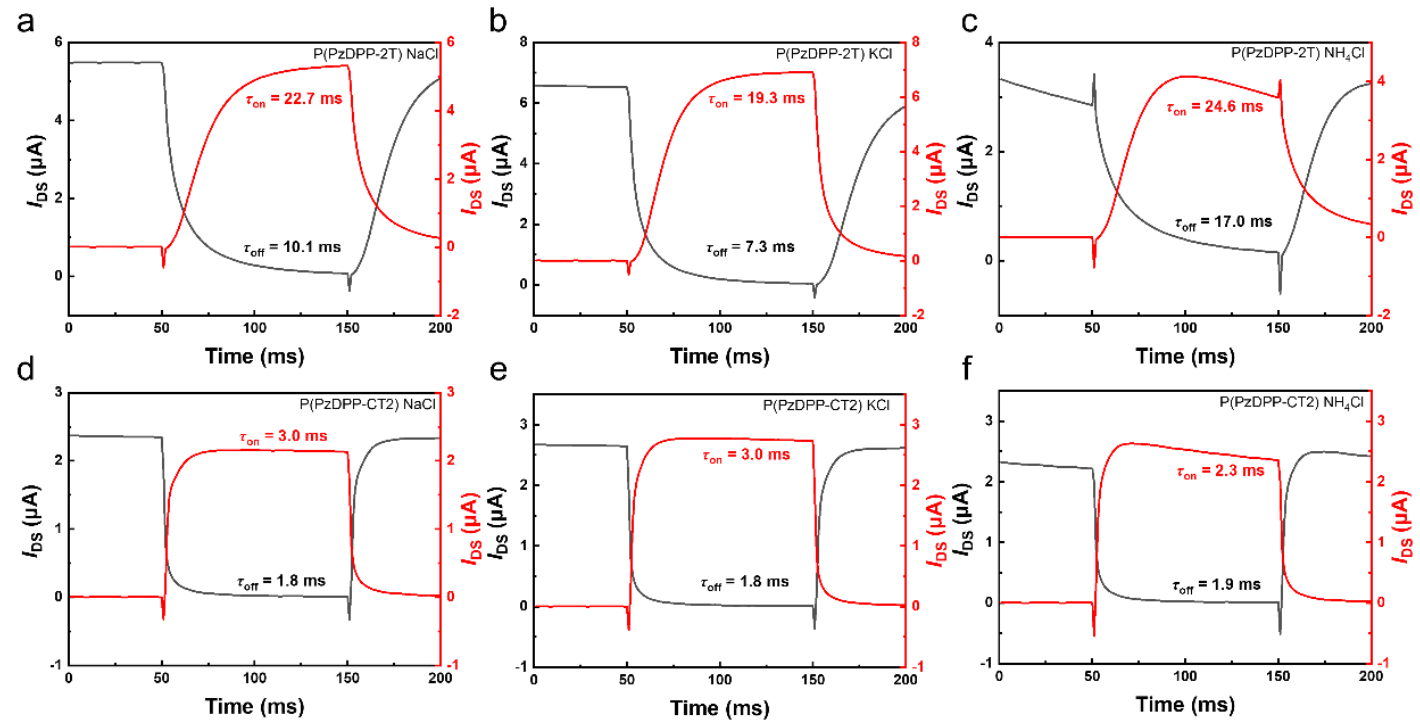

Figure S10 Transient on/off curves based on different electrolytes with $V_{\mathrm{GS}}$ of $0-0.8 \mathrm{~V}$ and $0-0.6 \mathrm{~V}$ for P(gPzDPP-2T) and P(gPzDPP-CT2), respectively. The electrolytes are $0.1 \mathrm{M}$ (a \& d) NaCl, (b \& e) $\mathrm{KCl}$, and (c \& f) $\mathrm{NH}_{4} \mathrm{Cl}$. The device was rinsed with deionized water between different electrolyte tests. 
a

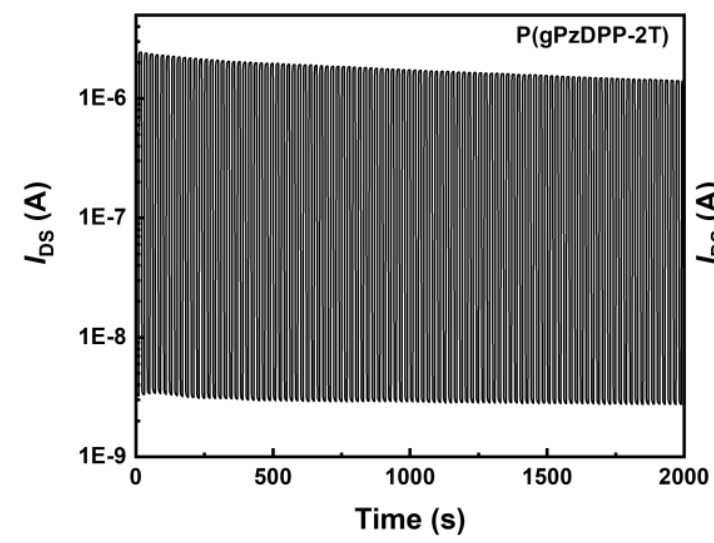

b

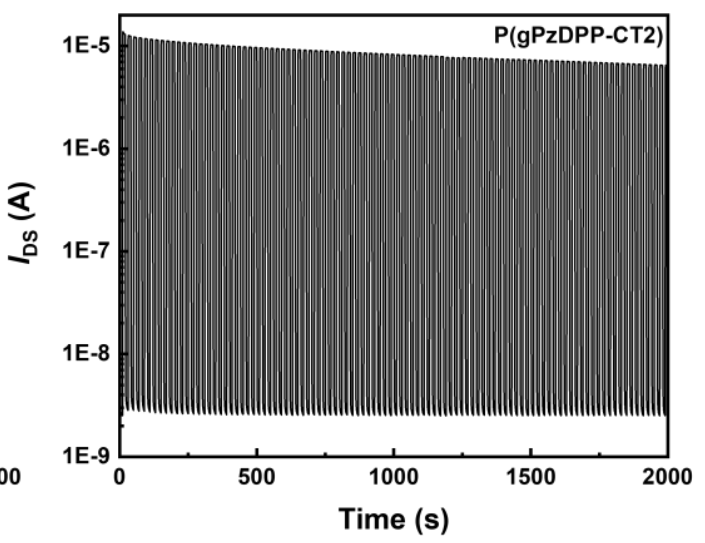

Figure S11 Long-term on-off switching of polymers in $0.1 \mathrm{M} \mathrm{NaCl}$ aqueous solution. $V_{\mathrm{DS}}=0.6 \mathrm{~V}$, a gate voltage pulse $V_{\mathrm{GS}}=0.7 \mathrm{~V}$ for (a) P(gPzDPP-2T), and $0.5 \mathrm{~V}$ for (b) P(gPzDPP-CT2) was applied for $10 \mathrm{~s}$, with an interval of $10 \mathrm{~s} . W / L=100 / 10 \mu \mathrm{m} .100$ cycles were repeated. The electrolyte was not deoxygenated.

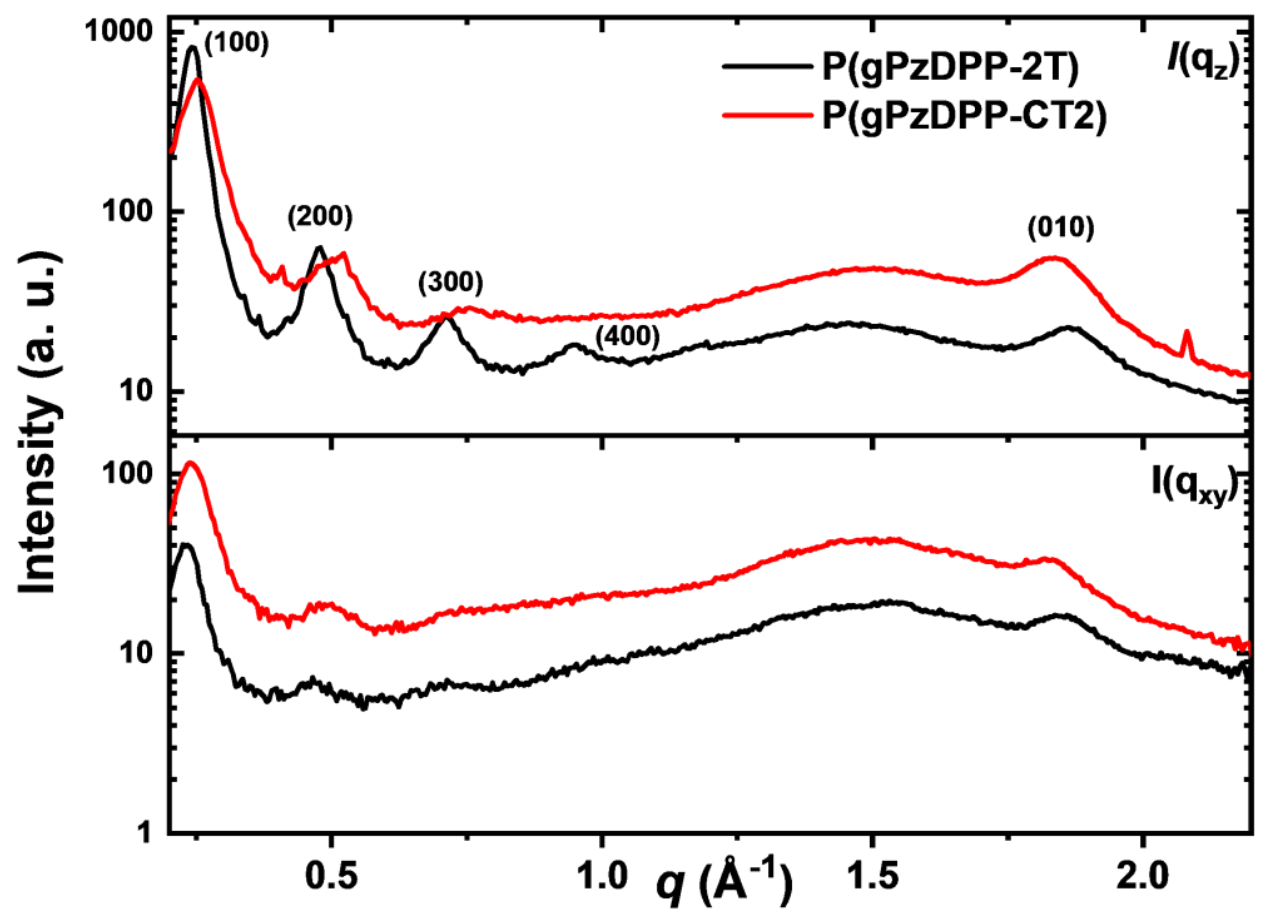

Figure S12 The corresponding line cuts of P(gPzDPP-2T) (black) and P(gPzDPP-CT2) (red). Cuts along the $q_{\mathrm{xy}}$ direction represent scattering in the in-plane direction, while the scattering of the $q_{\mathrm{z}}$ direction results from out-of-plane scattering. 


\section{Polymer Synthesis}

Scheme S1. Synthetic routes to the side chain 4 , the polymers and two stannyl compounds.

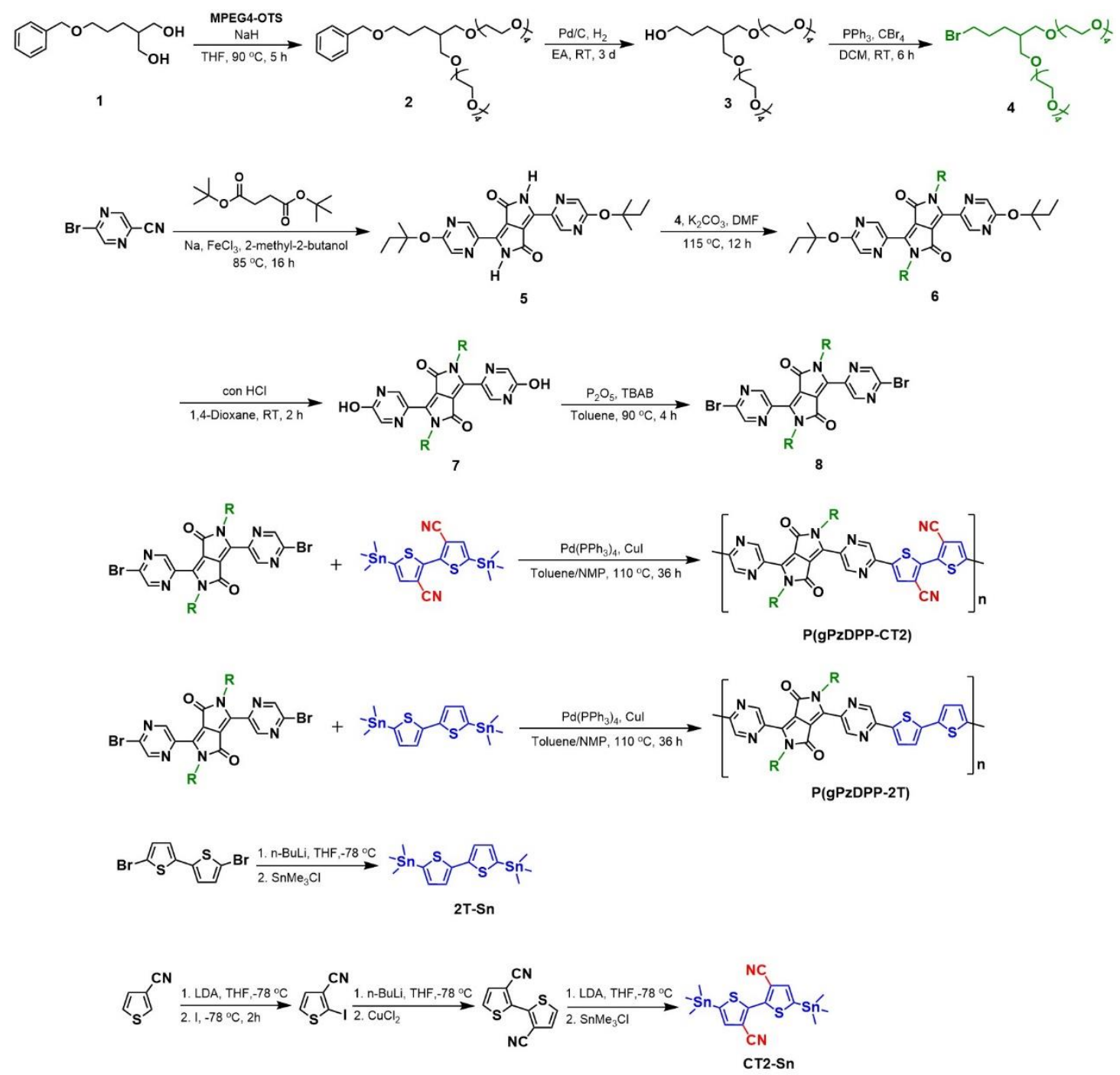

\section{Synthesis of compound 2}

Under nitrogen atmosphere, a $500 \mathrm{~mL}$ two-necked round bottom flask was added with MPEG4-OTS (16.9 g, $46.83 \mathrm{mmol}$ ) and $150 \mathrm{~mL}$ THF, sodium hydride (2.67 g, 111.3 mmol) was added slowly into the mixture, and the resulting was stirred at $60{ }^{\circ} \mathrm{C}$ for 30 min. After cooling to RT, compound $\mathbf{1}(5 \mathrm{~g}, 22.3 \mathrm{mmol})$ was dropwise into the mixture. And then, the resulting was heated at $70{ }^{\circ} \mathrm{C}$ for $12 \mathrm{~h}$. After the reaction was quenched with ethanol and water, the mixture was extracted with DCM and washed with water $\left(\mathrm{H}_{2} \mathrm{O}\right)$, and the residue was purified by silica gel column chromatography using ethly acetate $(\mathrm{EA}) /$ methyl alcohol $(\mathrm{MeOH})(v: v, 50 / 1)$ as eluent to give light yellow oily liquid 2 (7.43 g, 55\%). ${ }^{1} \mathrm{H}$ NMR ( $\left.\mathrm{CDCl}_{3}, 400 \mathrm{MHz}, \mathrm{TMS}\right), \delta(\mathrm{ppm}):$ 7.34-7.27 (m, 5H), 
$4.49(\mathrm{~s}, 2 \mathrm{H}), 3.64-3.40(\mathrm{~m}, 38 \mathrm{H}), 3.38$ (s, 6H), 1.88-1.85 (t, $J=12 \mathrm{~Hz}, 1 \mathrm{H}), 1.69-1.62$

$(\mathrm{t}, J=28 \mathrm{~Hz}, 2 \mathrm{H}), 1.44-1.38(\mathrm{t}, J=24 \mathrm{~Hz}, 2 \mathrm{H}) .{ }^{13} \mathrm{C} \mathrm{NMR}(100 \mathrm{MHz}, \mathrm{CDCl} 3), \mathrm{d}(\mathrm{ppm})$ : $140.61,128.35,127.63,127.49,72.89,71.95,71.84,70.71,70.63,70.61,70.59,70.54$, $70.52,70.50,59.06,38.96,27.27,25.22$.

\section{Synthesis of compound 3}

Under nitrogen atmosphere, $250 \mathrm{~mL}$ two-necked round bottom flask was added with $\mathrm{Pd} / \mathrm{C}(34.98 \mathrm{mg}, 0.33 \mathrm{mmol})$ and $50 \mathrm{~mL}$ EA. 2 ( $1 \mathrm{~g}, 1.66 \mathrm{mmol})$ was added the mixture, then under hydrogen atmosphere the mixture was stirred for 3 days. After diatomite suction filtration to collect the filtrate and vacuum distillation, a colorless oily liquid $\mathbf{3}$ was obtained (830.5 mg, 97.3\%). ${ }^{1} \mathrm{H} \mathrm{NMR}\left(\mathrm{CDCl}_{3}, 400 \mathrm{MHz}, \mathrm{TMS}\right), \delta$ (ppm): 3.653.56 (m, 36H), 3.48-3.44 (t, $J=16,2 \mathrm{H}), 3.38$ (s, 6H), 1.91-1.90 (m, 1H), 1.60-1.59 (m, 2H), 1.44-1.43 (m, 2H). ${ }^{13} \mathrm{C} \mathrm{NMR}(100 \mathrm{MHz}, \mathrm{CDCl} 3), \mathrm{d}(\mathrm{ppm}):$ 72.10, 71.93, 70.63, $70.61,70.59,70.56,70.51,70.48,62.77,59.04,38.69,30.13,24.85$.

\section{Synthesis of compound 4}

Under nitrogen atmosphere, triphenylphosphine (1.3 g, $4.96 \mathrm{mmol})$ and $10 \mathrm{~mL}$ DCM was cooled to $0{ }^{\circ} \mathrm{C} .3(1.17 \mathrm{~g}, 3.82 \mathrm{mmol})$, carbon tetrabromide $(1.64 \mathrm{~g}, 4.96 \mathrm{mmol})$, and $10 \mathrm{~mL}$ DCM solution were dropwise into the mixture. The reaction was stirred at RT for $4 \mathrm{~h}$. After the resulting mixture was washed with water, the residue was purified by silica gel column chromatography using EA as the eluent to give light yellow oily liquid 4 (800 mg, 57\%). ${ }^{1} \mathrm{H} \mathrm{NMR}\left(\mathrm{CDCl}_{3}, 400 \mathrm{MHz}, \mathrm{TMS}\right), \delta(\mathrm{ppm})$ : 3.66-3.61 (m, 24H), 3.57-3.54 (m, 8H), 3.47-3.37 (m, 12H), 1.95-1.86 (m, 3H), 1.52-1.46 (m, 2H). ${ }^{13} \mathrm{C}$ NMR(100 MHz, CDCl3), d (ppm): 71.88, 71.76, 70.58, 70.56, 70.52, 70.48, 70.46, 58.98, 38.52, 34.04, 30.45, 27.61. FTMS calcd. for $(\mathrm{M}+\mathrm{H})^{+}:$577.25091, Found: 577.257744 .

\section{Synthesis of compound 5}

Under nitrogen atmosphere, in $9 \mathrm{~mL}$ of tert-amyl alcohol, ferric chloride (6 mg) was added, and sodium $(0.21 \mathrm{~g}, 9.06 \mathrm{mmol})$ was added in batches. The mixture was heated at $115{ }^{\circ} \mathrm{C}$ for $2 \mathrm{~h}$. After cooling to $65^{\circ} \mathrm{C}, 5$-bromopyrazine-2-carbonitrile (1.0 g, 5.43 
mmol) was added, and di-tert-butyl succinate $(0.53 \mathrm{~g}, 2.26 \mathrm{mmol})$ and tert-amyl alcohol $(1 \mathrm{~mL})$ solution was added dropwise into the mixture. After the resulting mixture was heated at $85{ }^{\circ} \mathrm{C}$ for $16 \mathrm{~h}$ and cooling to RT, the mixture was washed with $\mathrm{H}_{2} \mathrm{O} / \mathrm{MeOH}$ $(v: v, 1.2 / 1)$, and then suction filtration to give red solids $\mathbf{5}(771 \mathrm{mg})$ as crude product. The crude product was dried and directly used in the subsequent reaction.

\section{Synthesis of compound 6}

Under nitrogen atmosphere, in $5 \mathrm{~mL}$ of $N, N$-dimethylformamide, 5 (237 mg, 0.55 mmol) and potassium carbonate $(300 \mathrm{mg}, 2.18 \mathrm{mmol})$ was added. After heating the mixture to $115^{\circ} \mathrm{C}, 4(723 \mathrm{mg}, 1.25 \mathrm{mmol})$ in DMF ( $\left.3 \mathrm{~mL}\right)$ was added dropwise into the mixture and stirred for $12 \mathrm{~h}$. After cooling to RT, the mixture was washed with water and extracted with DCM. The residue was purified by silica gel column chromatography using $\mathrm{EA} / \mathrm{MeOH}(v: v, 50 / 1)$ as the eluent to give a red solid $6(165 \mathrm{mg}$, 20.7\%). ${ }^{1} \mathrm{H} \mathrm{NMR}\left(\mathrm{CDCl}_{3}, 400 \mathrm{MHz}, \mathrm{TMS}\right), \delta$ (ppm): 9.78 (d, $\left.J=1.2,2 \mathrm{H}\right), 8.14-8.13$ (d, $J=1.2,2 \mathrm{H}), 4.26-4.18(\mathrm{t}, J=2.4 \mathrm{~Hz}, 4 \mathrm{H}), 3.65-3.59$ (m, 50H), 3.55-3.52 (m, 16H), 3.42-3.38 (m, 6H), 3.37 (s, $12 \mathrm{H}), 2.04-1.99$ (m, 4H), 1.88-1.85 (m, 4H), $1.67(\mathrm{~s}, 16 \mathrm{H})$, 1.42-1.36 (m, 4H), 0.95-0.92 (t, $J=12 \mathrm{~Hz}, 6 \mathrm{H}) .{ }^{13} \mathrm{C} \mathrm{NMR}(100 \mathrm{MHz}, \mathrm{CDCl} 3), \mathrm{d}(\mathrm{ppm})$ : $162.26,160.21,145.64,142.45,135.96,135.10,109.00,85.42,77.05,76.73,72.13$, $70.57,70.49,62.79,59.05,38.75,38.68,33.56,30.13,25.72,24.85,8.35$.

\section{Synthesis of compound 7}

A $50 \mathrm{~mL}$ round bottom flask was added with $6(165 \mathrm{mg})$ and 1,4-dioxane $(3 \mathrm{~mL})$, and conc. $\mathrm{HCl} 0.5 \mathrm{~mL}$ was added dropwise. The mixture was stirred at RT for $2 \mathrm{~h}$. After the solvent was evaporated, the crude product $7(155 \mathrm{mg})$ was obtained, which can be used directly for the next step.

\section{Synthesis of compound 8}

A $25 \mathrm{~mL}$ Schlenk tube was added with tetrabutylammonium bromide (TBAB) (85 mg, $0.26 \mathrm{mmol}$ ) and phosphorus pentoxide (150 mg, $1.06 \mathrm{mmol})$, and 7 (140 $\mathrm{mg}, 0.11 \mathrm{mmol})$ in toluene $(5 \mathrm{~mL})$ was added subseqently. The mixture was freeze-pump-thaw three 
times and then heated to $90{ }^{\circ} \mathrm{C}$ for $2 \mathrm{~h}$. After cooling to RT, the residue was dried and was purified by silica gel chromatography to give 8 (41 mg, 26.7\%). ${ }^{1} \mathrm{H} \mathrm{NMR}\left(\mathrm{CDCl}_{3}\right.$, $400 \mathrm{MHz}, \mathrm{TMS}), \delta$ (ppm): 10.04 (s, 2H), 8.73 (s, 2H), 4.20 (s, 4H), 3.64-3.60 (m, 46H), $3.54(\mathrm{~s}, 16 \mathrm{H}), 3.41(\mathrm{~m}, 10 \mathrm{H}), 3.37(\mathrm{~s}, 12 \mathrm{H}), 1.69-1.67(\mathrm{~m}, 4 \mathrm{H}), 1.44(\mathrm{~m}, 2 \mathrm{H}), 1.26-1.23$ (m, 4H). ${ }^{13} \mathrm{C}$ NMR(100 MHz, CDCl3), d (ppm): 161.56, 150.20, 148.29, 147.25, 146.47, $143.65,142.15,142.04,141.99,141.67,141.43,112.02,71.91,71.66,70.58,70.55$, 70.49, 70.47, 59.03, 42.93, 38.70, 29.68, 27.47, 25.66, 24.24, 19.78. FTMS calcd. for $(\mathrm{M}+\mathrm{H})^{+}:$1441.551536, Found: 1441.548671.

\section{Synthesis of polymer P(gPzDPP-2T)}

A $25 \mathrm{~mL}$ Schlenk tube was added with tetratriphenylphosphine palladium $(0.51 \mathrm{mg}$, $0.44 \mu \mathrm{mol})$, cuprous iodide $(0.17 \mathrm{mg}, 0.88 \mu \mathrm{mol}), 5,5$ '-bis(trimethylstannyl)-2,2'bithiophene (10.9 mg, $22.18 \mu \mathrm{mol}), 8(32.97 \mathrm{mg}, 22.84 \mu \mathrm{mol})$, and toluene $/ \mathrm{N}$ methylpyrrolidone $(3 \mathrm{~mL} / 3 \mathrm{~mL})$. The mixture was freeze-pump-thaw three times and then heated to $120^{\circ} \mathrm{C}$ for $36 \mathrm{~h}$. After cooling the reaction mixture to room temperature, diethylphenylazothioformamide $(3 \mathrm{mg}$ ) was added to remove the catalyst, and the resulting mixture was stirred at $80{ }^{\circ} \mathrm{C}$ for $1 \mathrm{~h}$. The reaction mixture was poured into 50 $\mathrm{mL}$ hexane to precipitate the polymer and filtered. The polymer solid was placed in a Soxhlet extractor and extracted with hexane, methanol, acetone, and chloroform. The chloroform solution was concentrated under reduced pressure and then poured into 20 $\mathrm{mL}$ hexane to reprecipitate the polymer. The suspension was filtered and dried in vacuum to afford the polymer. $\mathrm{M}_{\mathrm{n}}$ : $90889 \mathrm{Da} ; \mathrm{M}_{\mathrm{w}}: 315283$ Da; PDI: 3.468874.

\section{Synthesis of polymer P(gPzDPP-CT2)}

A $25 \mathrm{~mL}$ Schlenk tube was added Tetratriphenylphosphine palladium $(0.48 \mathrm{mg}, 0.42$ $\mu \mathrm{mol})$ and cuprous iodide $(0.16 \mathrm{mg}, 0.84 \mu \mathrm{mol}), 5,5$ '-bis(trimethylstannyl)-[2,2'bithiophene]-3,3'-dicarbonitrile (11.14 mg, $20.56 \mu \mathrm{mol})$ and 8 (30.27 mg, $20.97 \mu \mathrm{mol})$ and toluene/N-methylpyrrolidone $(3 \mathrm{~mL} / 3 \mathrm{~mL})$ was added. The tube was charged with nitrogen through a freeze-pump-thaw cycle three times. The sealed tube was heated to $120{ }^{\circ} \mathrm{C}$ and stirred for $36 \mathrm{~h}$. After cooling the reaction mixture to room temperature, 
diethylphenylazothioformamide ( $3 \mathrm{mg}$ ) was added to remove the catalyst and the resulting mixture was stirred at $80{ }^{\circ} \mathrm{C}$ for $1 \mathrm{~h}$. The reaction mixture was poured into 50 $\mathrm{mL}$ hexane to precipitate the polymer and filtered. The polymer solid was placed in a Soxhlet extractor and extracted with hexane, methanol, acetone, and chloroform. The chloroform solution was concentrated under reduced pressure and then poured into 20 $\mathrm{mL}$ hexane to reprecipitate the polymer. The suspension was filtered and dried in vacuum to afford the polymer. $\mathrm{M}_{\mathrm{n}}: 64746 \mathrm{Da} ; \mathrm{M}_{\mathrm{w}}$ : $228591 \mathrm{Da}$; PDI: 3.530562 .

\section{Synthesis of stannyl compound 2T-Sn}

2T-Sn was synthesized according to the literature. ${ }^{[7]}$

\section{Synthesis of stannyl compound CT2-Sn}

CT2-Sn was synthesized according to our previous work. ${ }^{[8]}$

\section{The Characterization Data of New Compounds}

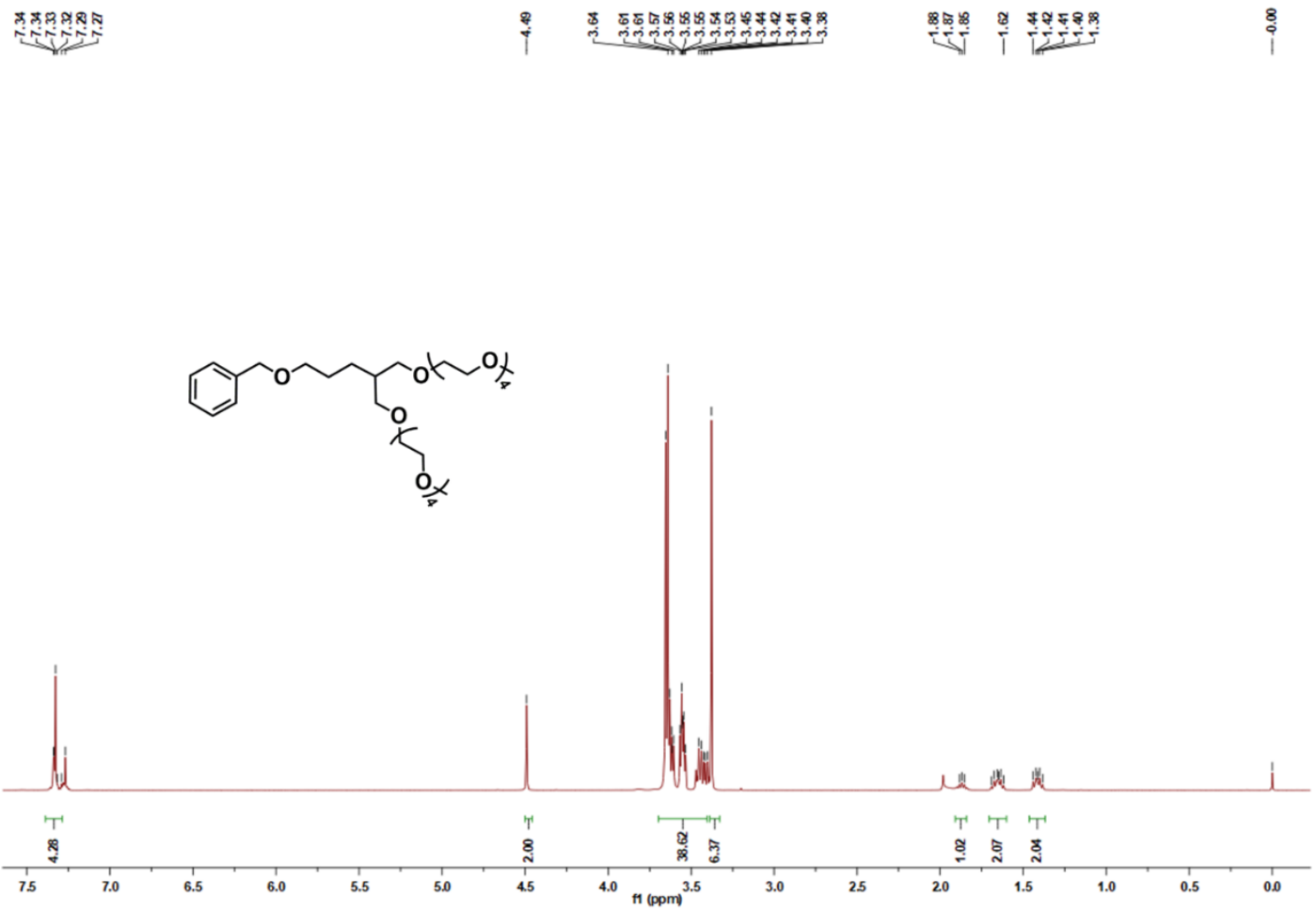


Figure S13 ${ }^{1} \mathrm{H}$ NMR spectrum of compound 2

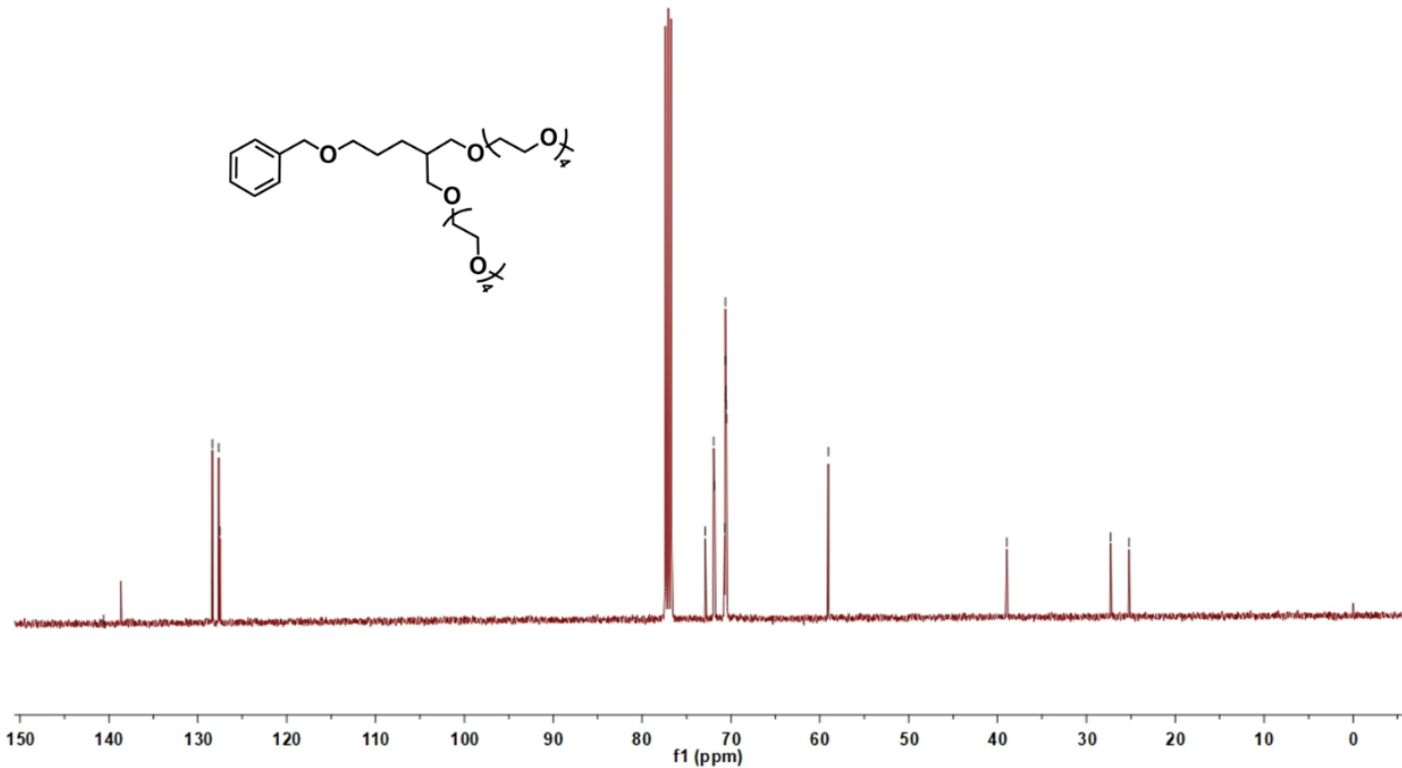

Figure S14 ${ }^{13} \mathrm{C}$ NMR spectrum of compound 2

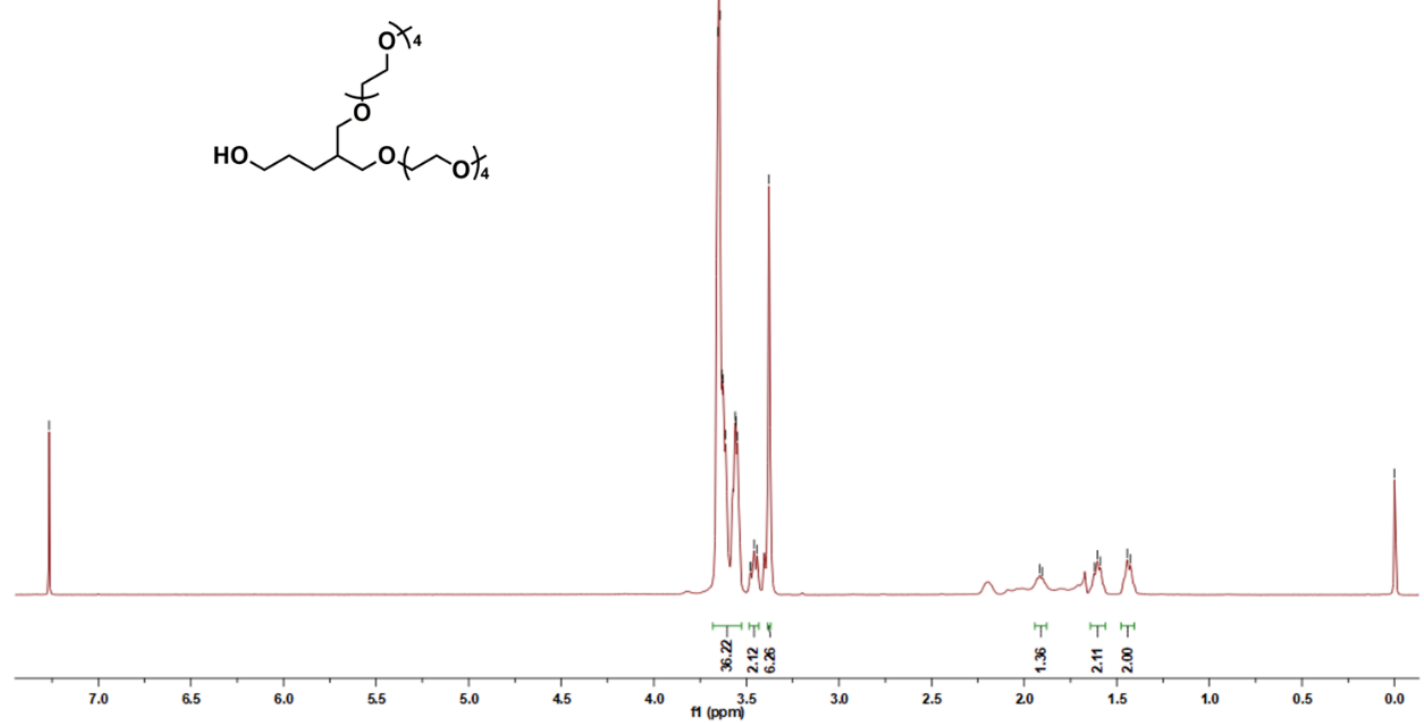

Figure S15 ${ }^{1} \mathrm{H}$ NMR spectrum of compound 3 


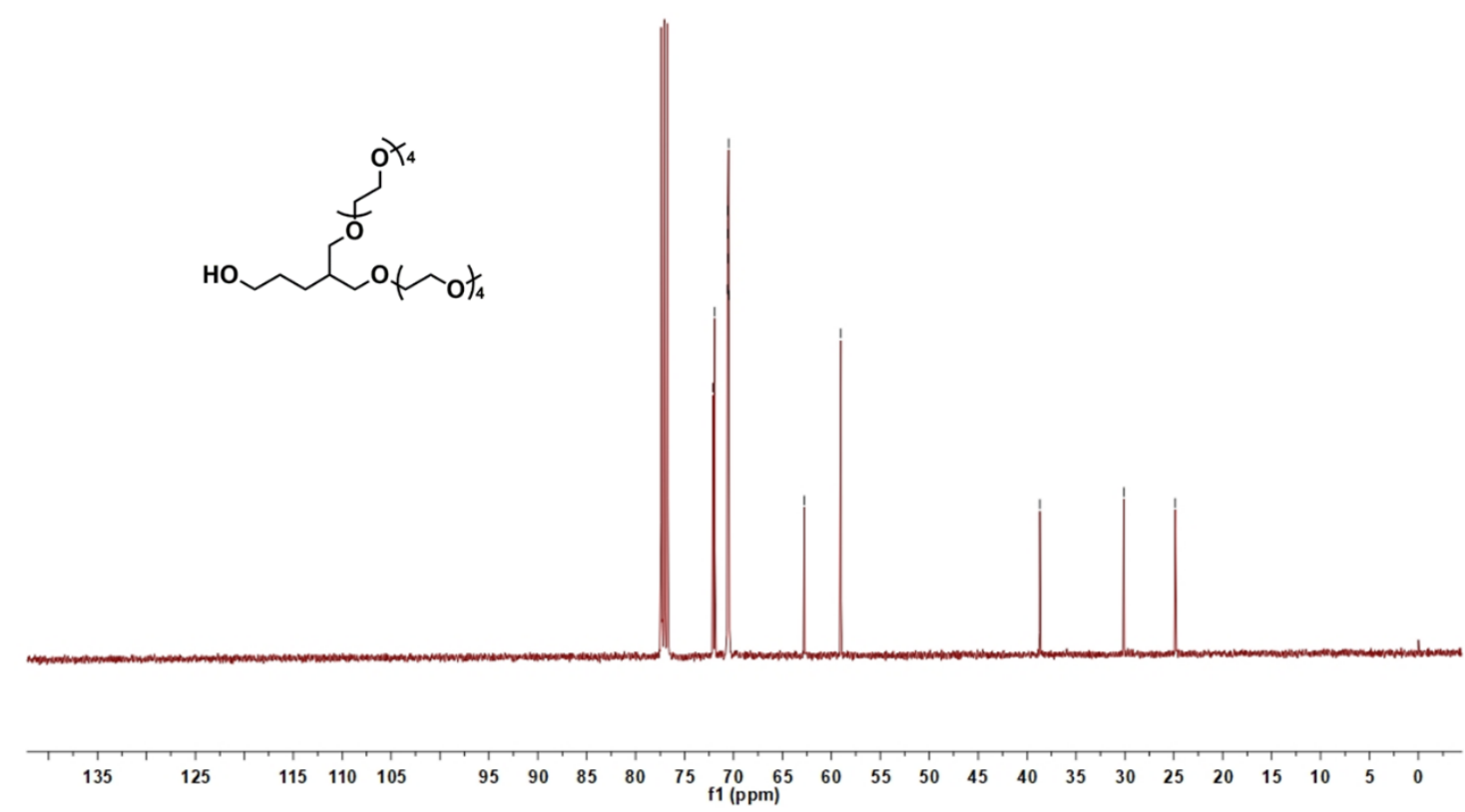

Figure S16 ${ }^{13} \mathrm{C}$ NMR spectrum of compound 3

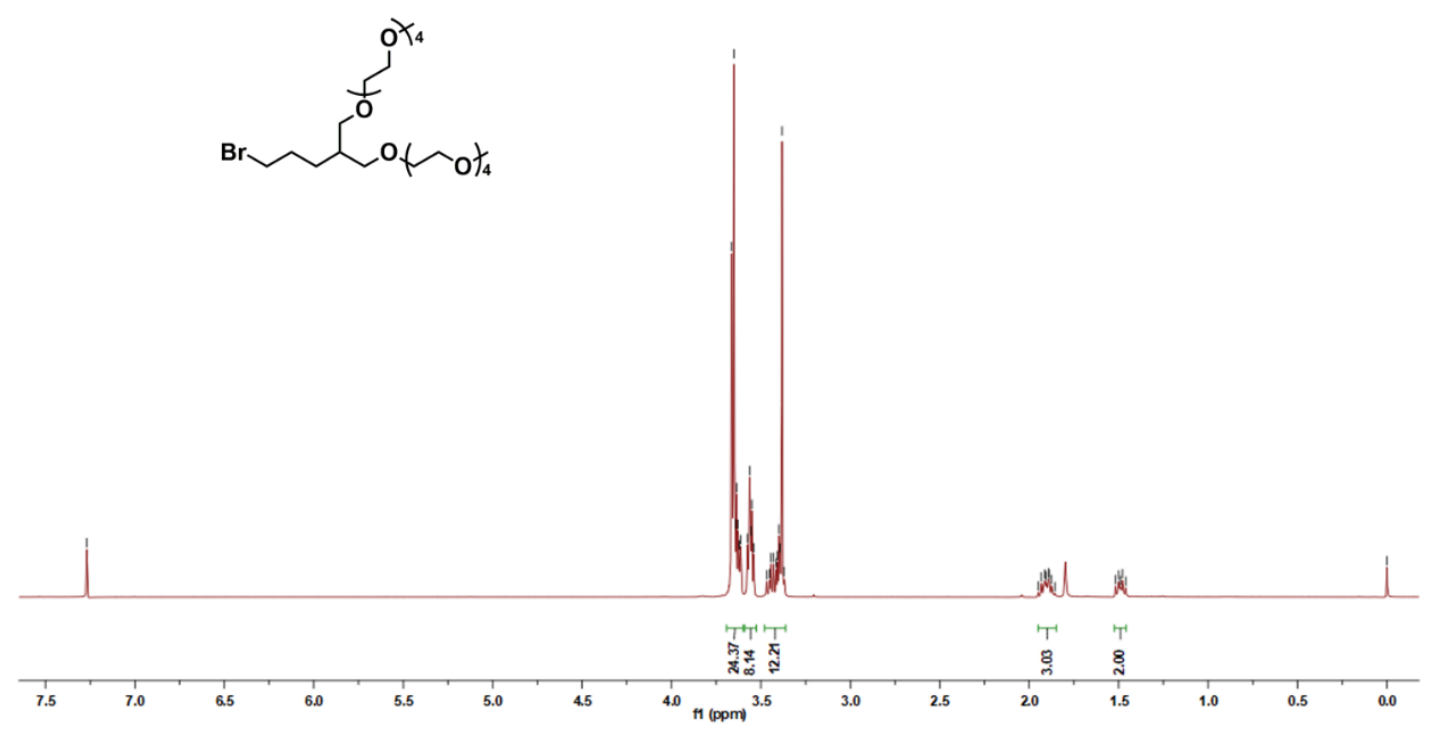

Figure S17 ${ }^{1} \mathrm{H}$ NMR spectrum of compound 4 


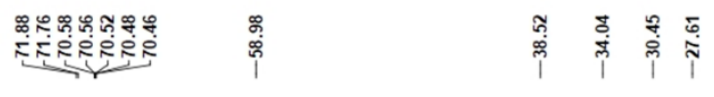

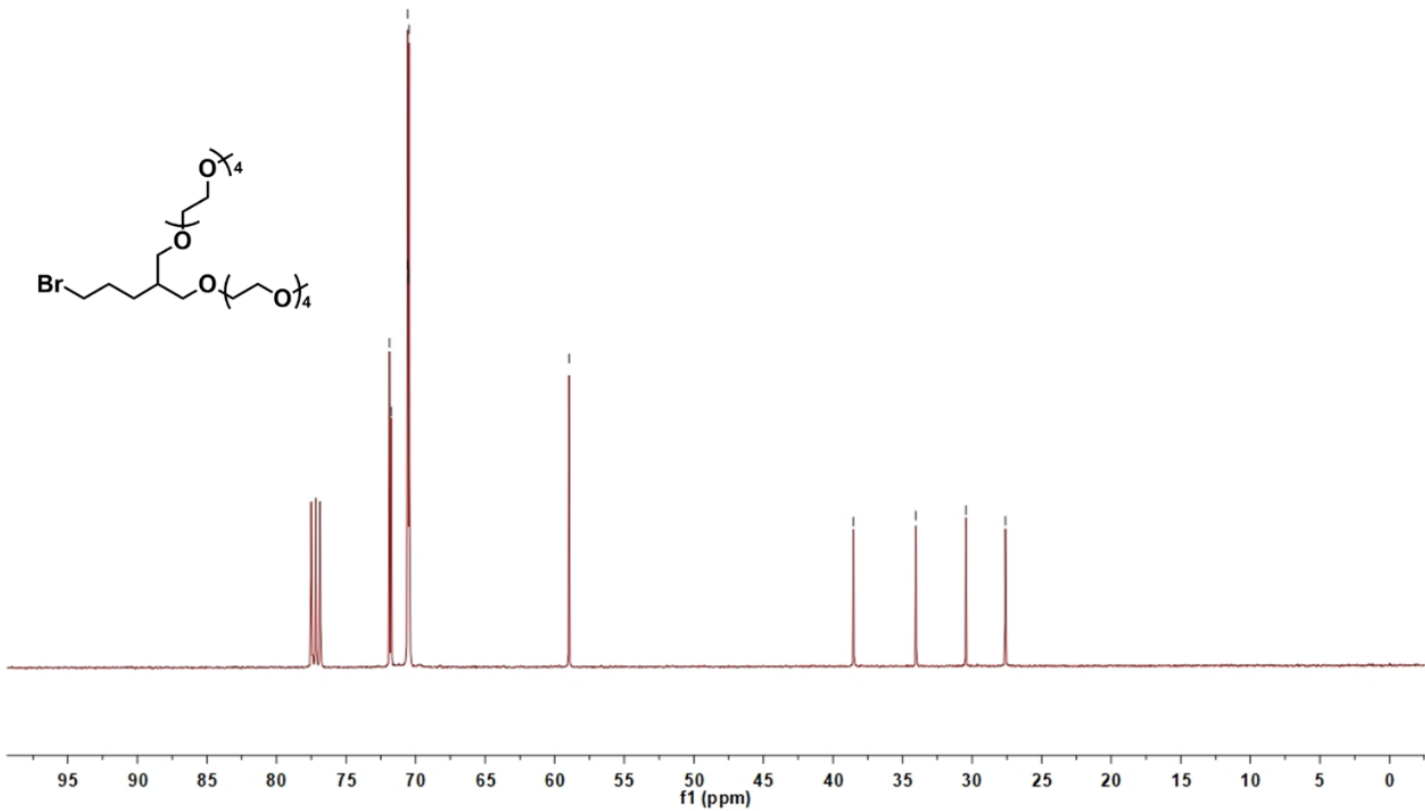

Figure S18 ${ }^{13} \mathrm{C}$ NMR spectrum of compound 4
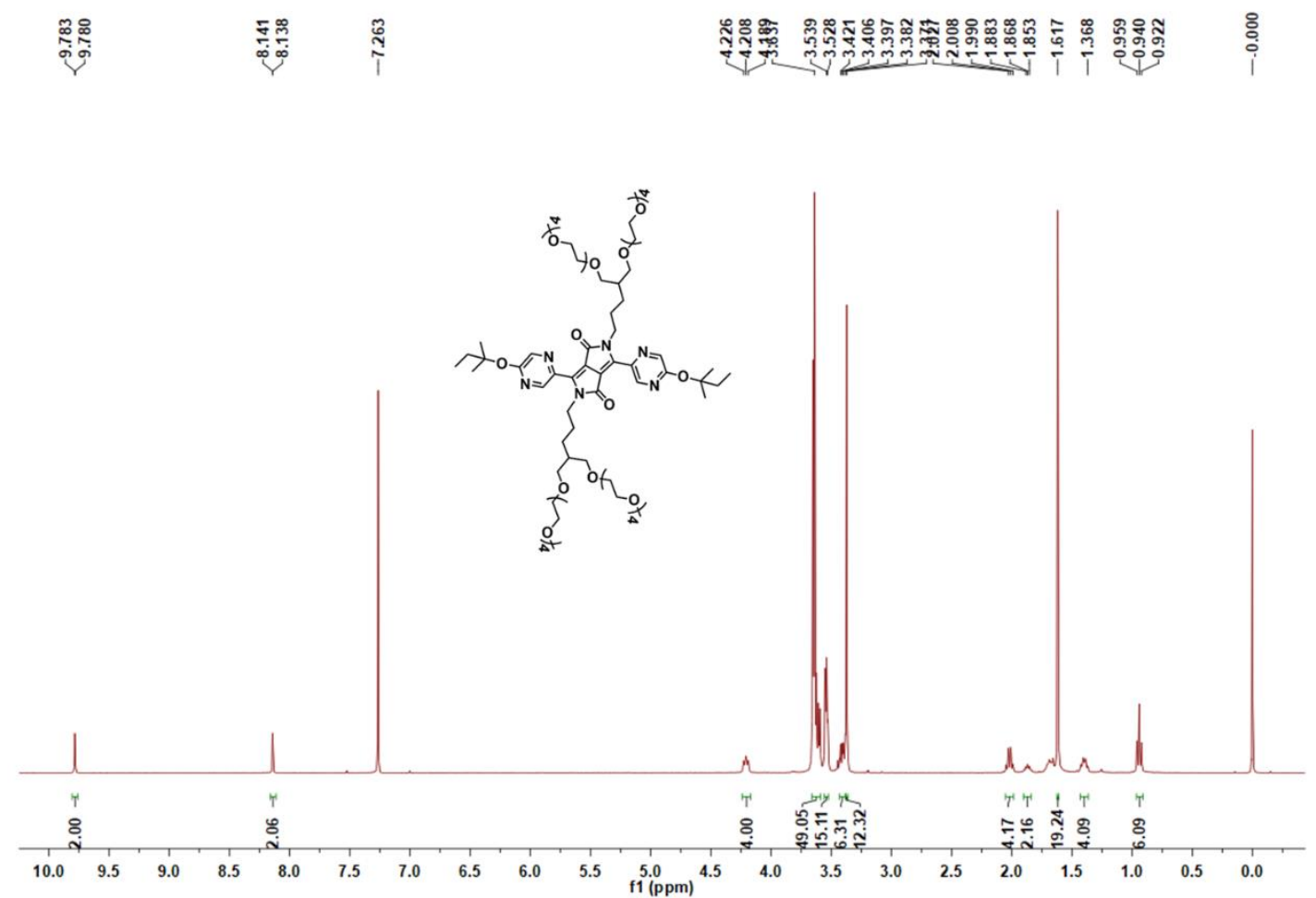

Figure S19 ${ }^{1} \mathrm{H}$ NMR spectrum of compound 6 


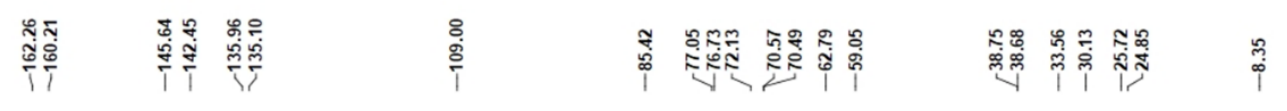
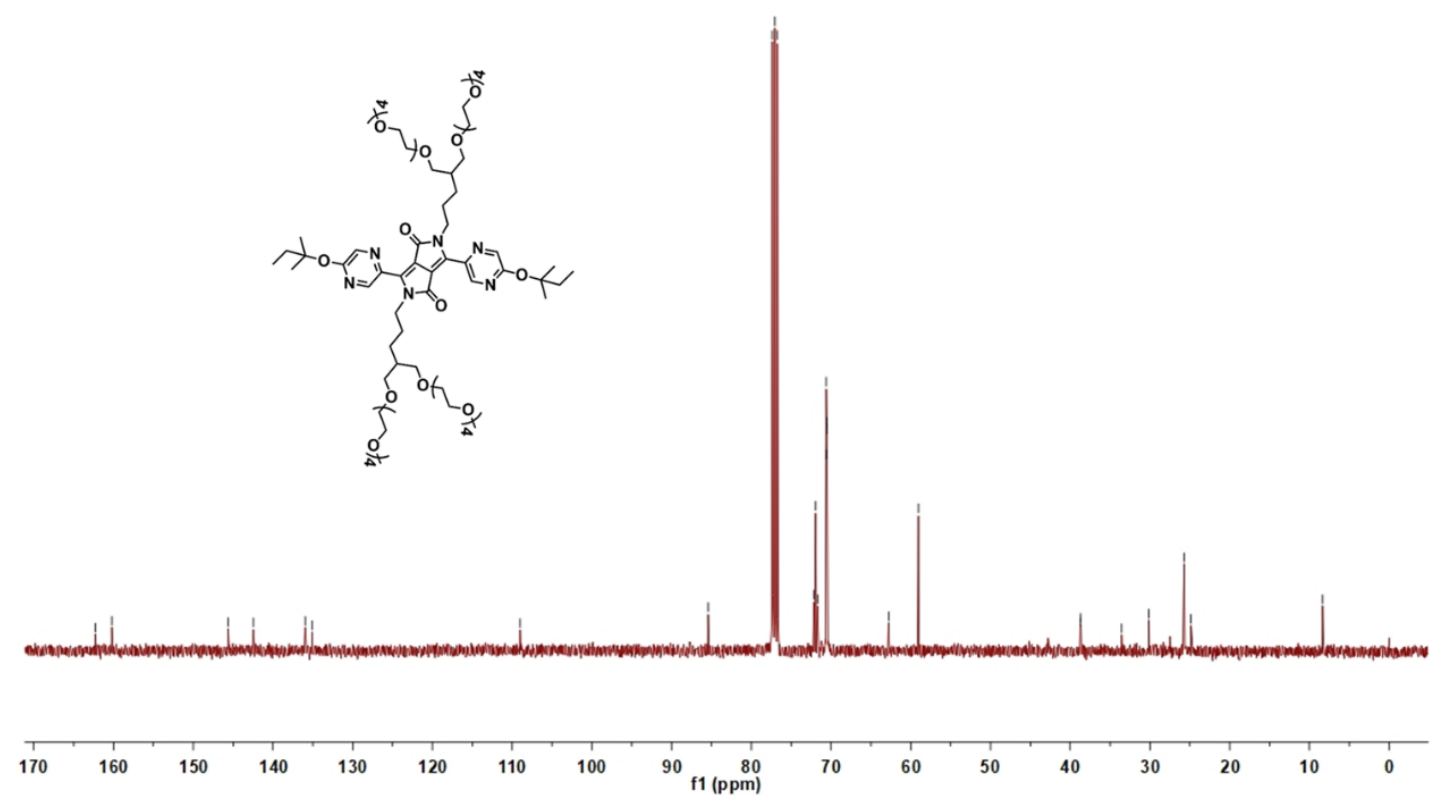

Figure S20 ${ }^{13} \mathrm{C}$ NMR spectrum of compound 6

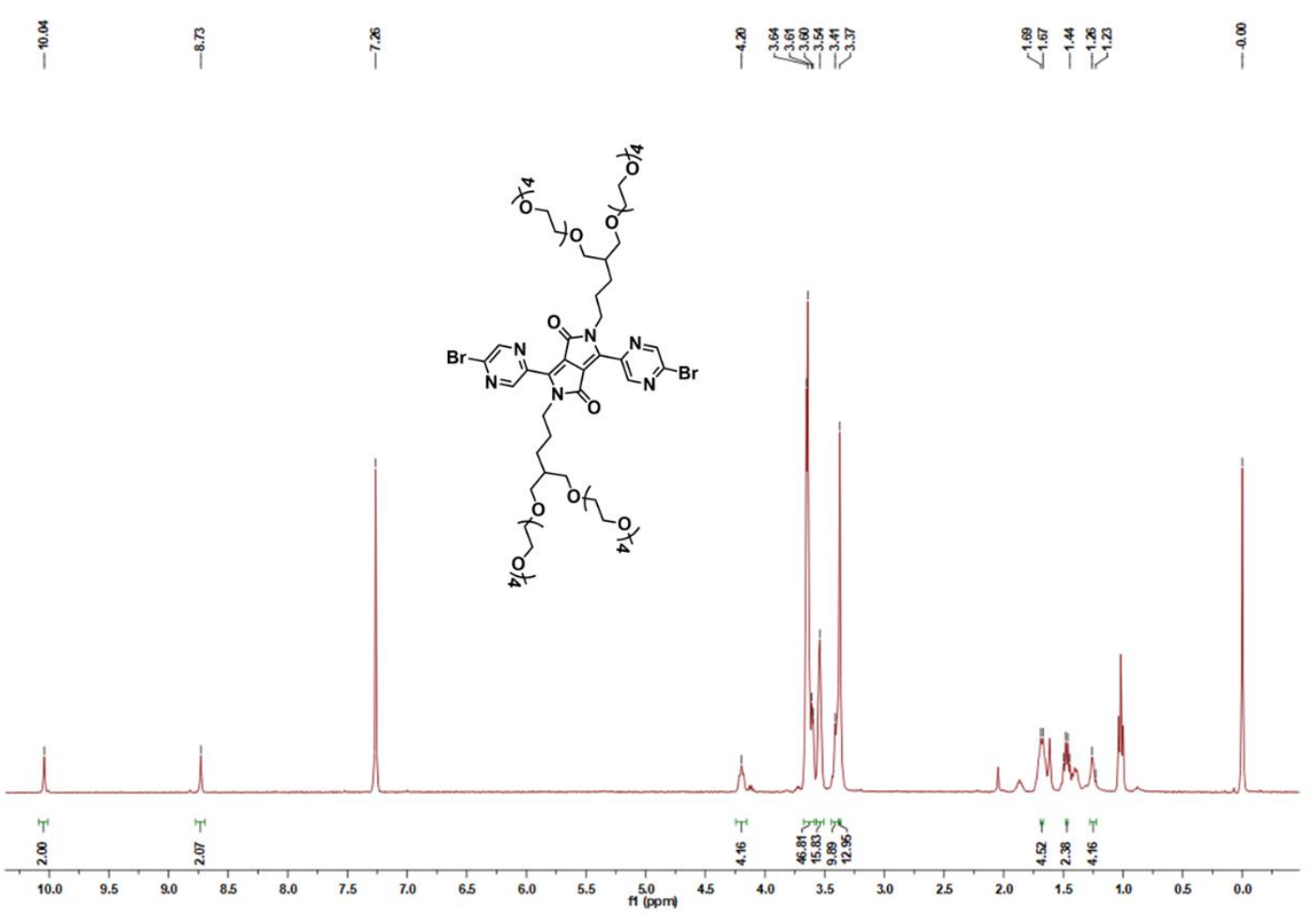

Figure S21 ${ }^{1} \mathrm{H}$ NMR spectrum of compound 8 

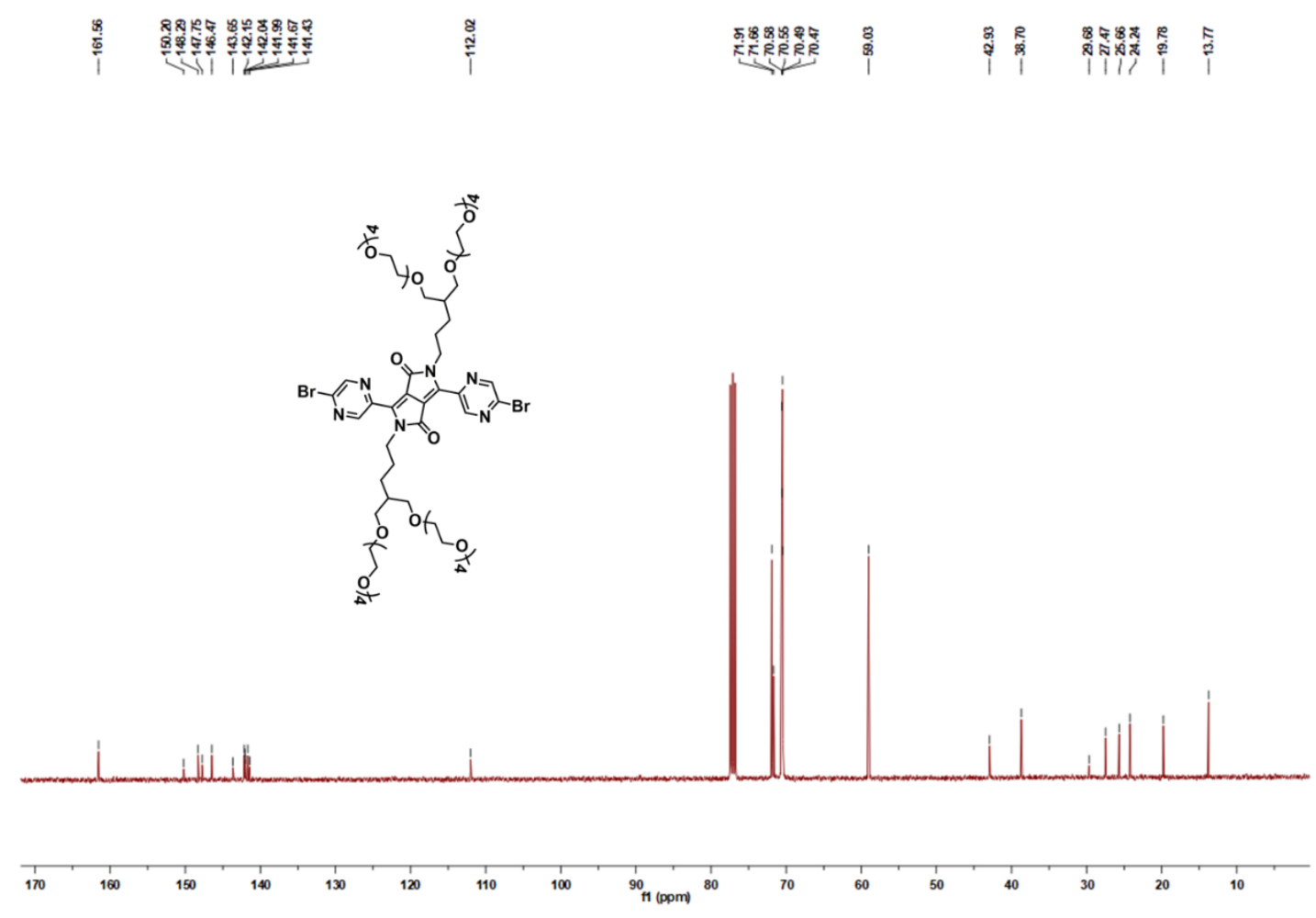

Figure S22 ${ }^{13} \mathrm{C}$ NMR spectrum of compound 8

\section{จำำำำ}

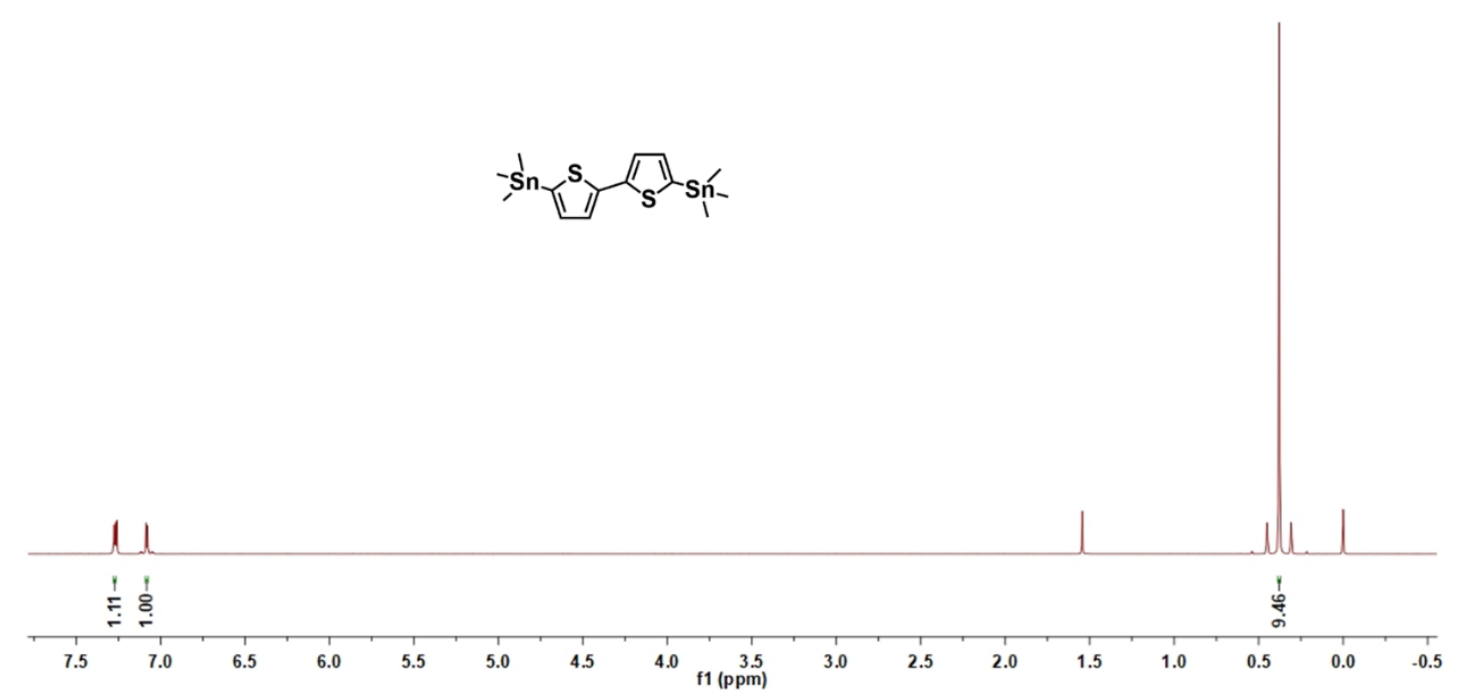

Figure S23 ${ }^{1} \mathrm{H}$ NMR spectrum of compound 2T-Sn 


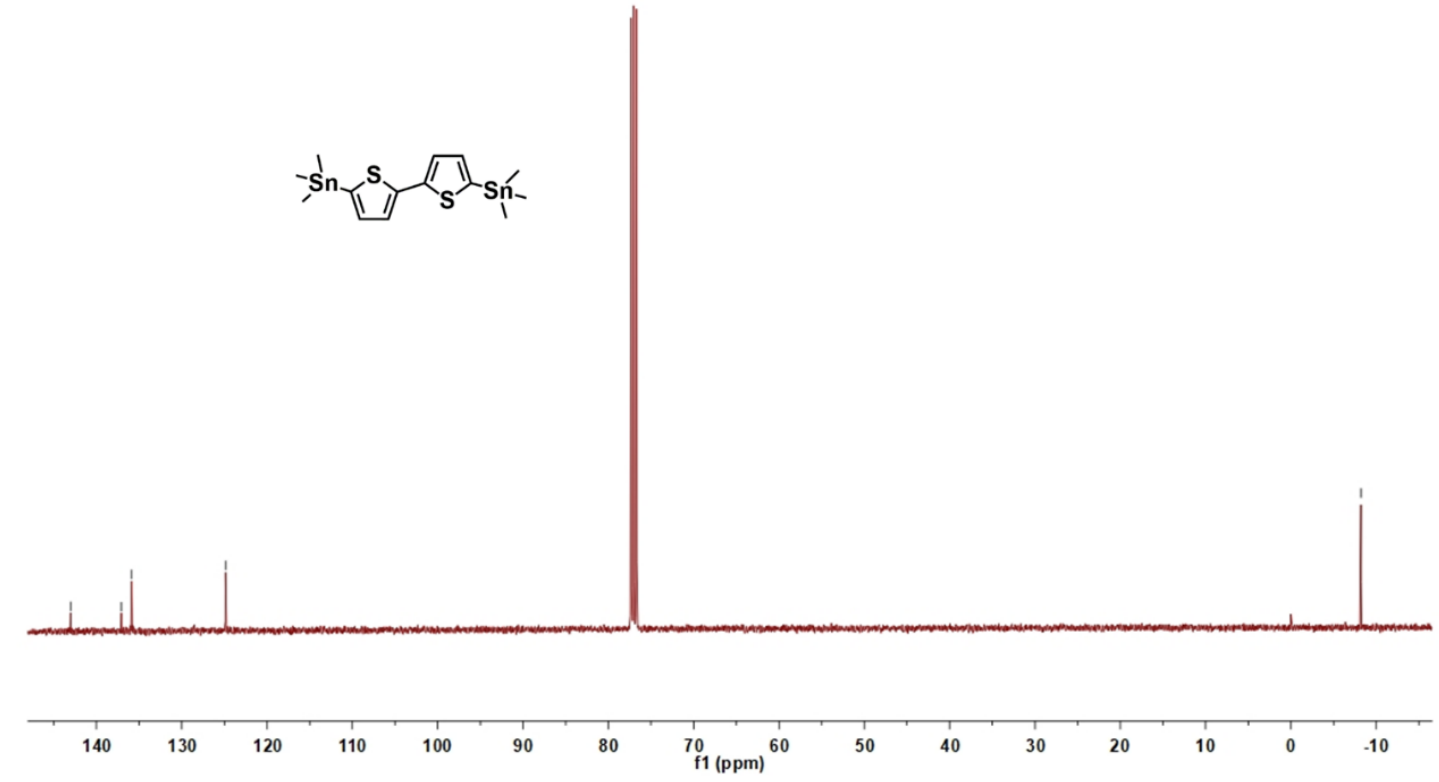

Figure S24 ${ }^{13} \mathrm{C}$ NMR spectrum of compound 2T-Sn
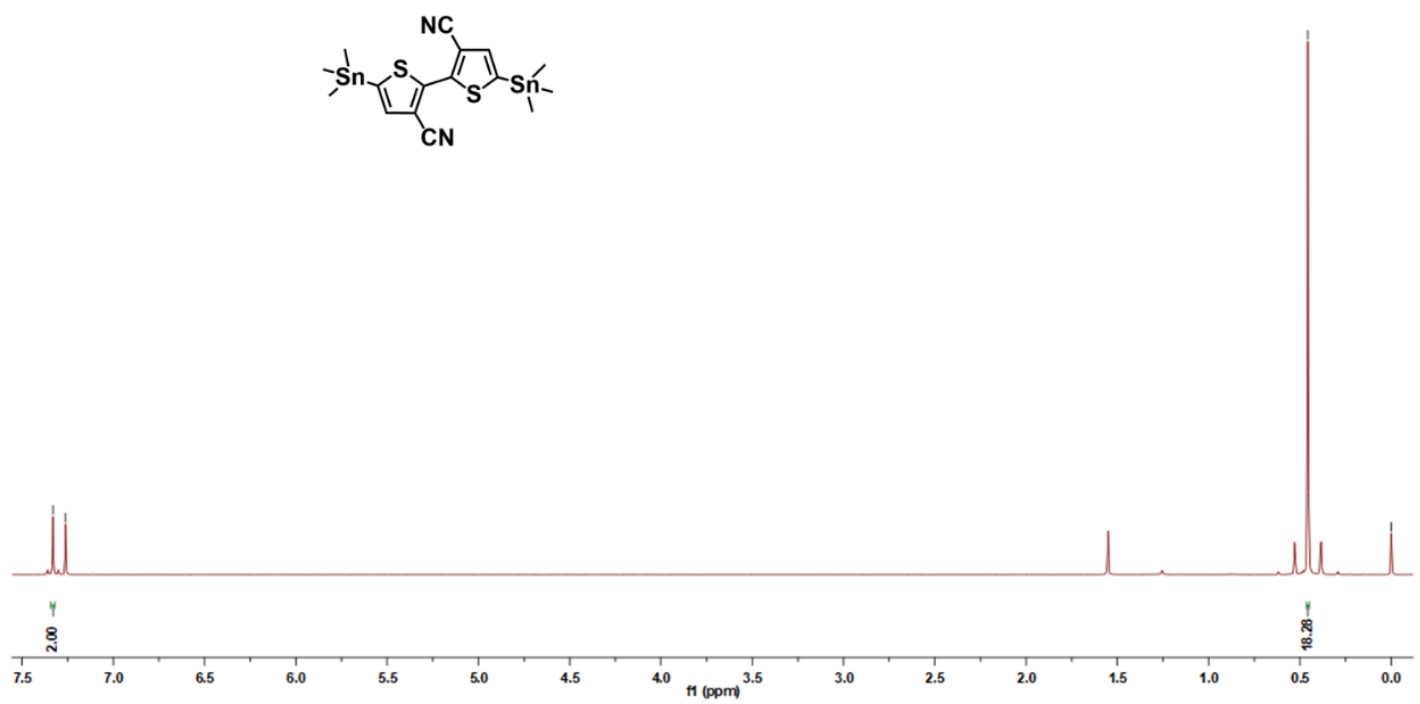

Figure S25 ${ }^{1} \mathrm{H}$ NMR spectrum of compound CT2-Sn 


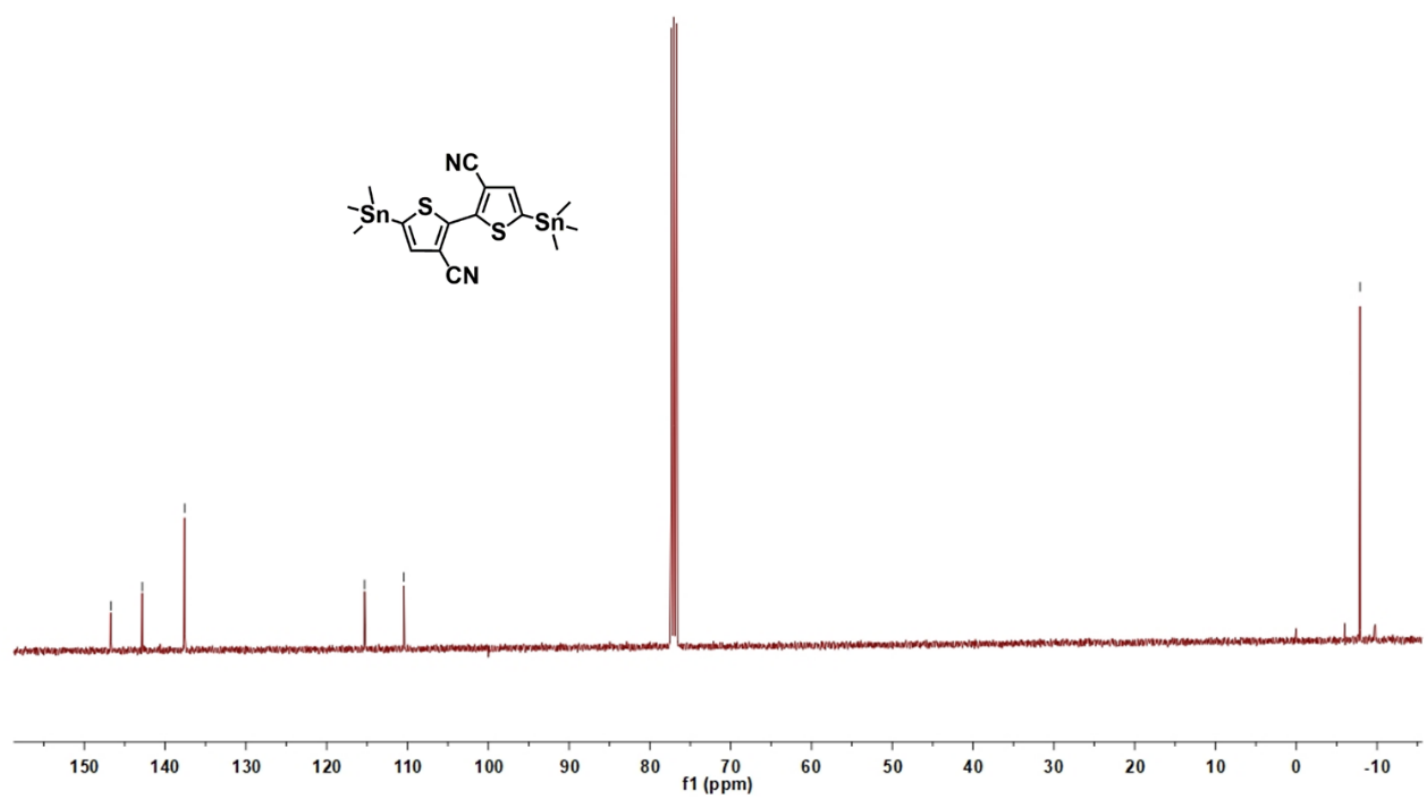

Figure S26 ${ }^{13} \mathrm{C}$ NMR spectrum of compound CT2-Sn

\section{References}

[1]. Jenekhe, S. A.; Yi, S. J., Appl. Phys. Lett., Efficient Photovoltaic Cells from Semiconducting Polymer Heterojunctions. 2000, 77, 2635-2637.

[2]. Sun, H.; Vagin, M.; Wang, S.; Crispin, X.; Forchheimer, R.; Berggren, M.; Fabiano, S., $A d v$. Mater., Complementary Logic Circuits Based on High-Performance N-Type Organic Electrochemical Transistors. 2018, 30, 1704916.

[3]. Giovannitti, A.; Nielsen, C. B.; Sbircea, D. T.; Inal, S.; Donahue, M.; Niazi, M. R.; Hanifi, D. A.; Amassian, A.; Malliaras, G. G.; Rivnay, J.; McCulloch, I., Nat. Commun., N-Type Organic Electrochemical Transistors with Stability in Water. 2016, 7, 13066.

[4]. Chen, X.; Marks, A.; Paulsen, B. D.; Wu, R.; Rashid, R. B.; Chen, H.; Alsufyani, M.; Rivnay, J.; McCulloch, I., Angew. Chem. Int. Ed., N-Type Rigid Semiconducting Polymers Bearing Oligo(Ethylene Glycol) Side Chains for High-Performance Organic Electrochemical Transistors. 2021, 60, 9368-9373.

[5]. Feng, K.; Shan, W.; Ma, S.; Wu, Z.; Chen, J.; Guo, H.; Liu, B.; Wang, J.; Li, B.; Woo, H. Y.; Fabiano, S.; Huang, W.; Guo, X., Angew. Chem. Int. Ed., Fused Bithiophene Imide DimerBased N-Type Polymers for High-Performance Organic Electrochemical Transistors. 2021, 60, 24198-24205.

[6]. Pethig, R., Ieee Transactions on Electrical Insulation, Dielectric-Properties of BiologicalMaterials - Biophysical and Medical Applications. 1984, 19, 453-474.

[7]. Ha, J. S.; Kim, K. H.; Choi, D. H., J. Am. Chem. Soc., 2,5-Bis(2-Octyldodecyl)Pyrrolo[3,4- 
C]Pyrrole-1,4-(2h,5h)-Dione-Based Donor-Acceptor Alternating Copolymer Bearing 5,5'Di(Thiophen-2-Yl)-2,2'-Biselenophene Exhibiting 1.5 Cm2.V(-1).S(-1) Hole Mobility in Thin-Film Transistors. 2011, 133, 10364-10367.

[8]. Yan, X.; Xiong, M.; Li, J. T.; Zhang, S.; Ahmad, Z.; Lu, Y.; Wang, Z. Y.; Yao, Z. F.; Wang, J. Y.; Gu, X.; Lei, T., J. Am. Chem. Soc., Pyrazine-Flanked Diketopyrrolopyrrole (Dpp): A New Polymer Building Block for High-Performance N-Type Organic Thermoelectrics. 2019, 141, 20215-20221. 